\title{
Systematic testing of hybrid PV-thermal (PVT) solar collectors in steady-state and dynamic outdoor conditions
}

\author{
Ilaria Guarracino ${ }^{\mathrm{a}}$, James Freeman ${ }^{\mathrm{a}}$, Alba Ramos ${ }^{\mathrm{a}}$, Soteris A. Kalogirou ${ }^{\mathrm{b}}$, Nicholas J. Ekins-Daukes ${ }^{\mathrm{c}}$, \\ Christos N. Markides ${ }^{a, *}$ \\ ${ }^{a}$ Clear Energy Processes Laboratory (CEP), Department of Chemical Engineering, Imperial College London \\ ${ }^{b}$ Department of Mechanical Engineering, Cyprus University of Technology \\ ${ }^{c}$ Blackett Laboratory, Department of Physics, Imperial College London
}

\begin{abstract}
Hybrid photovoltaic-thermal (PVT) collectors have been proposed for the combined generation of electricity and heat from the same area. In order to predict accurately the electrical and thermal energy generation from hybrid PVT systems, it is necessary that both the steady-state and dynamic performance of the collectors is considered. This work focuses on the performance characterisation of non-concentrating PVT collectors under outdoor conditions. A novel aspect of this work is the application of existing methods, adapted from relevant international standards for flat plate and evacuated tube solar-thermal collectors, to PVT collectors for which there is no formally established testing methodology at present. Three different types of PVT collector are tested, with a focus on the design parameters that affect their thermal and electrical performance during operation. Among other results, we show that a PVT collector suffers a $10 \%$ decrease in thermal efficiency when the electricity conversion is close to the maximum power point compared to open-circuit mode, and that a poor thermal contact between the PV laminate and the copper absorber can lead to a significant deterioration in thermal performance. The addition of a glass cover improves the thermal efficiency, but causes electrical performance losses that vary with the glass transmittance and the solar incidence angle. It is found that the reduction in electrical efficiency at large incidence angles is more significant than that due to elevated temperatures representative of water-heating applications. Dynamic performance is characterised by imposing a step change in irradiance in order to quantify the collector time constant and effective heat capacity. This paper demonstrates that PVT collectors are characterised by a slow thermal response in comparison to ordinary flat plate solar-thermal collectors, due to the additional thermal mass of the PV layer. A time constant of $\sim 8 \mathrm{~min}$ is measured for a commercial PVT module, compared to $<2$ min for a flat plate solar-thermal collector. It is also concluded that the use of a lumped, first-order dynamic model to represent the thermal mass of the PVT collector is not appropriate under certain irradiation regimes and may lead to inaccurate predictions of the system performance. This paper outlines a procedure for the testing and characterisation of solar collectors, provides valuable steady-state and dynamic performance characterisation
\end{abstract}

\footnotetext{
${ }^{*}$ Corresponding author

Email address: c.markides@imperial.ac.uk (Christos N. Markides)
} 
data for various PVT collector designs, and also provides a framework for the application of this data in a system model to provide annual performance predictions in a range of geographical settings.

Keywords: hybrid PVT collectors, solar collectors, collector performance analysis, experimental characterisation of solar collectors, dynamic modelling

\section{Nomenclature}

\section{Symbols}

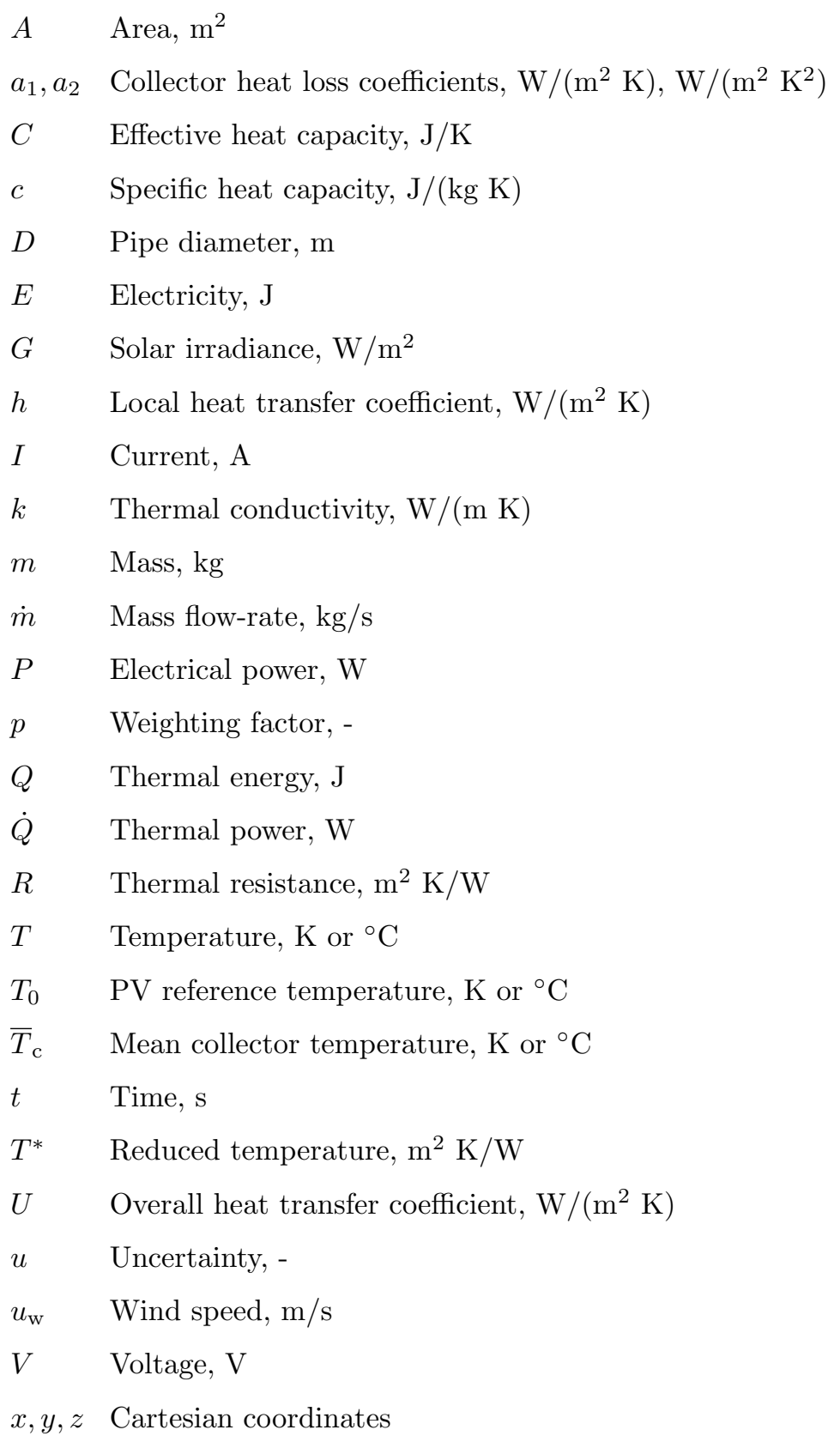

\section{Greek Symbols}




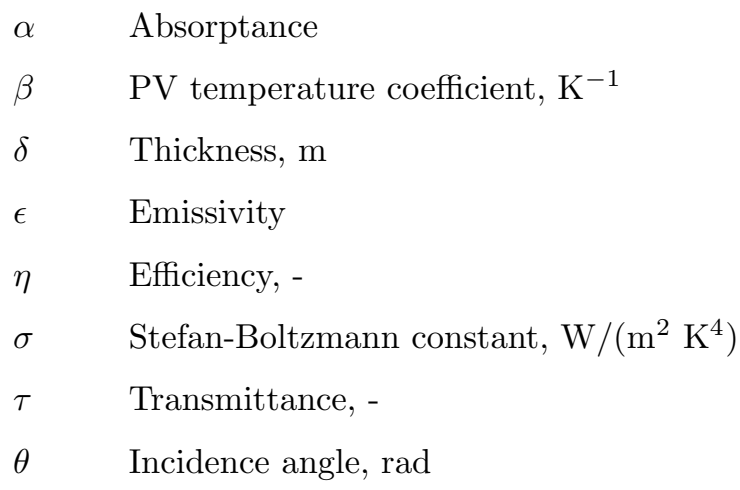

\section{Subscripts}

0 reference conditions

A area related

a ambient

AB absorber

avg average

b bonding

c collector

CD conduction

d daily/diurnal

E electrical

exp experimental

f fluid

g glass

gap air gap

i inlet

meas measured

o optical

o outlet

oc open circuit

p pipe

pred predicted

PV photovoltaic/photovoltaic layer

sc short circuit

t tank

TH thermal

wt weighted-component method 


\section{Introduction}

Non-concentrating solar photovoltaic (PV) panels are a mature technology that is highly suitable for the distributed generation of electricity in the built environment, while solar-thermal (ST) collectors can provide thermal energy for a diverse range of applications from domestic hot water and space heating in homes to thermodynamic engines, refrigerators and heat pumps [1]. More recently, "hybrid" PV-thermal (PVT) collectors have also been proposed, which combine PV modules with a heat-recovery configuration in order to provide simultaneous electrical and thermal outputs from the same array area 2]. The thermal, electrical and economic performance of PVT systems has been found to be highly dependent on various design and operational considerations such as materials and geometry [3], mode of circulation [4, relative sizes of the PV and thermal absorber areas [5], and required temperature and application of the thermal output [6]. In order to predict accurately the performance of solar-thermal or hybrid PVT systems with respect to their potential to provide heat, cooling and/or electricity, the collectors must be characterised in terms of their steady-state and dynamic performance [7].

Appropriate testing methods for conventional solar-thermal collectors, such as those decribed in the European Standard EN 12975-2 [8], are well established in Europe. Performance data are published as standard by manufacturers and testing institutions and are freely available for comparison via various online resources such as the Institute for Solar Energy (SPF) database [9]. By comparison, the PVT market is relatively small at present and test data that can be used for developing and validating predictive models for these collectors is scarce.

Recently, several authors have focused on the experimental characterisation of PVT collectors to obtain reliable data on their operation and performance. Generally the experimental investigations into PVT collectors are performed to evaluate the effect of various design parameters on the thermal and electrical efficiencies with the aim of identifying the potential for improvements. Most investigations to date have been performed on unglazed PVT liquid collectors.

Cremers et al. 10 investigated the potential improvement of the thermal contact between the PV module and thermal absorber in a plastic design, while also reducing thermal losses with rear shielding. Kim and Kim [11 investigated the thermal contact between the PV module and rear absorber for a fully-wetted absorber configuration and for a more conventional sheet-and-tube collector. The same authors also evaluated the potential reduction of the heat loss coefficient achieved with a glass cover [12. Lammle et al. 13 . recently investigated the effect of the solar cell emissivity on the thermal efficiency of a glazed PVT panel by applying a selective coating on the solar cells. The selective coating was found to reduce the heat losses by

$80 \%$ while the electrical output dropped by only $3 \%$. In another effort to improve thermal efficiency and to enhance the active cooling of the solar cells, the use of high-conductivity nano ferrofluids was proposed by Ghadiri et al. 14, while silica/water nanofluids were used in the experimental investigation by Sardarabadi et al. [15]. It was demonstrated that the use of these fluids results in an improvement of the thermal efficiency 
of $4-5 \%$ relative to water.

The aforementioned studies focus predominantly on the steady-state collector performance, however, the dynamic behaviour of solar-thermal and PVT collectors has an important bearing on their performance under time-varying irradiance conditions, the extent of which may vary across different geographical locations. EN 12975-2 includes both an experimental and a calculation-based procedure for characterising the dynamic performance of solar collectors through the determination of an effective thermal capacity parameter. The calculation-based procedure is typically preferred in practice due to its greater simplicity, although its accuracy has been a matter of critical discussion in subsequent reviews [16. The experimental procedure, on the other hand, requires suitable conditions when performed outdoors and can therefore be costly and time-consuming [17].

The aim of the present paper is to establish a procedure for the testing of PVT collectors under real weather conditions in steady-state and dynamic operation, and to identify the main design and operating parameters that influence the electrical and thermal performance. Glazed and unglazed PVT collectors are tested and the effect of the glass cover and the quality of the thermal contact between the PV module and the rear absorber is analysed. The effective thermal capacity parameter obtained using the experimental and the calculationbased procedures in EN 12975-2 are compared. The accurate prediction of solar collector behaviour is of fundamental importance for ensuring that the system is designed properly and does not underperform or fail; while improved models of PVT systems are required for optimisation of the design and operating parameters in order to achieve higher electrical and thermal energy yields and increased energy savings. It is demonstrated here that hybrid collectors are characterised by a large thermal mass that should be considered when modelling the system in order to provide an accurate prediction of the thermal performance under time-varying irradiance conditions. In what follows, the experimental methods are described in Section 2 , and the results of the PVT collector characterisation tests are presented in Section 3 Diurnal performance data for the various PVT collectors are evaluated in Section 4 and compared to simulations performed using a simple lumped first-order dynamic model and a more detailed three-dimensional dynamic collector model developed in earlier work. Finally the conclusions are presented in Section 5

\section{Experimental methods}

Tests were performed on four PVT collectors, each of a different design and construction. The collectors are shown in Fig. 1] and are described as follows: a commercial PVT module (M1); an unglazed PVT module with 65\% PV covering factor (M2U); a glazed PVT module with 65\% PV covering factor (M2G); and a glazed module with 100\% PV covering factor (M3). The majority of the tests were performed on a custom-built apparatus (described below) at the Cyprus University of Technology (CUT) in Limassol $\left(34.7^{\circ} \mathrm{N}, 33.0^{\circ} \mathrm{E}\right)$.

Some additional tests were performed at the Applied Energy Laboratory (AELab), a certified institute for solar collector testing in Nicosia $\left(35.2^{\circ} \mathrm{N}, 33.4^{\circ} \mathrm{E}\right)$ [18. 


\subsection{Experimental apparatus}

The experimental apparatus consists of closed-loop system represented schematically in Fig. 2. The PVT collector was installed on a south-oriented frame with a $37^{\circ}$ inclination angle. The system also includes a $150 \mathrm{~L}$ hot water storage tank with an inlet port located at the top and an outlet port located at the bottom. A Grundfos UPS 180 pump was used to circulate water around the system [19]. The collector flow-rate was controlled by adjusting the needle valve V4 located at the collector inlet and by opening or closing a bypass branch using valve V7. The flow-rate was measured using an analogue volumetric flow meter with an estimated precision of $\pm 5 \%$. The PVT module's current-voltage $(I-V)$ characteristic and the electrical power output at the maximum power point (MPP) were measured using a PVPM 2540C measurement device [20].

(a)

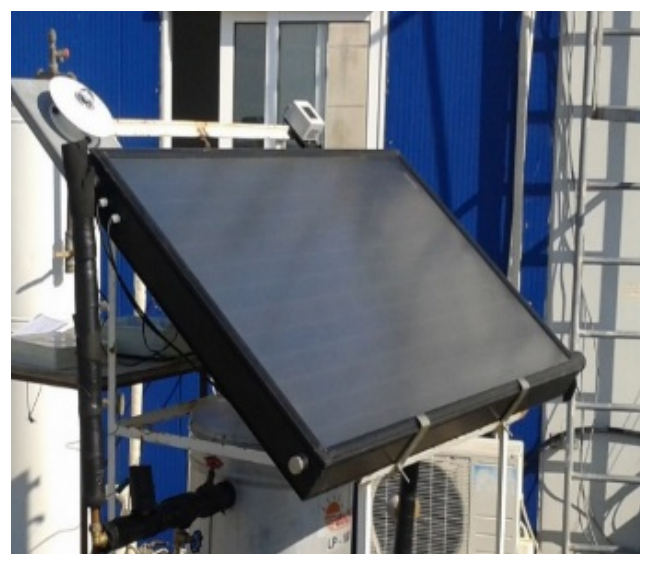

(c) (b)

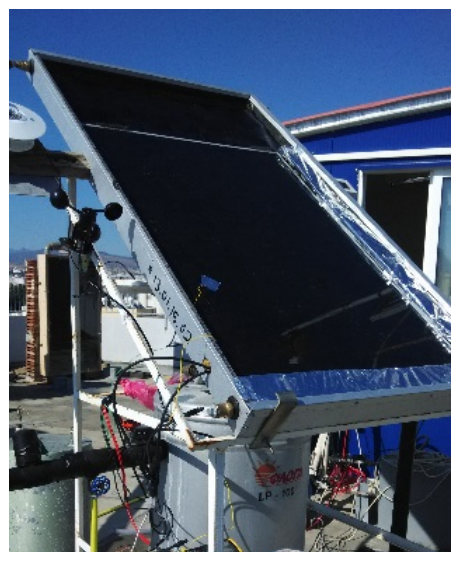

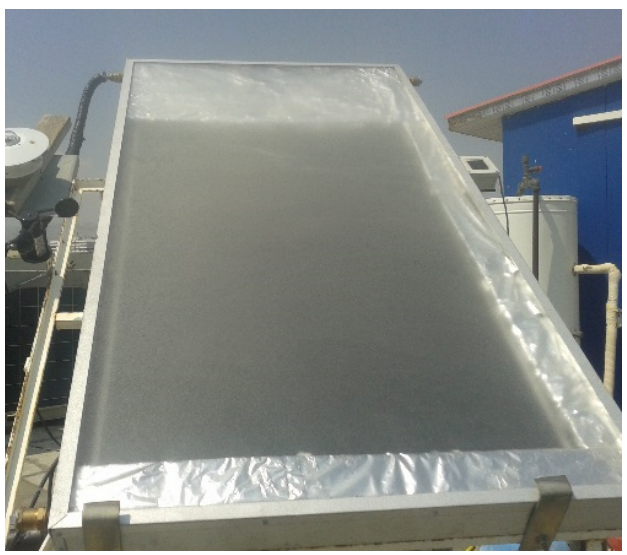

Figure 1: (a) Commercial PVT module (M1); (b) Unglazed PVT module with $65 \%$ covering factor (M2U); (c) Glazed PVT module with $100 \%$ covering factor (M3).

The ambient temperature $T_{\mathrm{a}}$, collector inlet temperature $T_{1}$, outlet temperature $T_{2}$ and the temperature at the back of the PV module were measured using calibrated K-type thermocouples. The fluid inlet temperature 


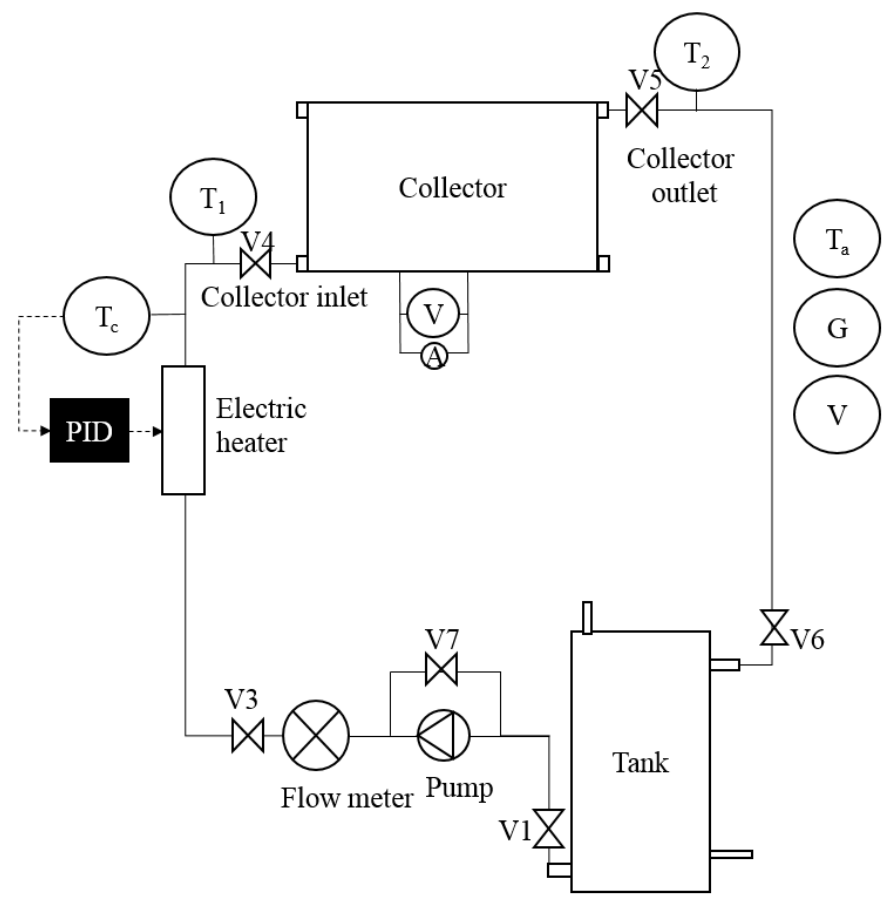

Figure 2: Schematic of the closed loop system for PVT testing in Limassol, Cyprus University of Technology.

was controlled using a $3 \mathrm{~kW}$ electric heater and PID controller taking an input from thermocouple $T_{\mathrm{c}}$. The global irradiance received on the inclined plane of the collector was measured using an Eppley PSP precision spectral pyranometer [21]. Measurements from the thermocouples and the pyranometer were logged at an interval of $1 \mathrm{~s}$ using an Omega DAQPRO-5300 portable data acquisition unit. The local wind speed, ambient temperature and horizontal global irradiance were also monitored using a Davis Vantage Pro2 weather station 22] located near the collector. In particular, the wind speed measurement was required in order to ensure that the tests were performed under similar conditions for directly comparable results.

A brief analysis was conducted to determine the most suitable time resolution for the solar irradiance measurements. On a clear day, solar irradiance varies slowly and predictably with the position of the sun in the sky, and hourly-resolution data is often acceptable for modelling of solar-thermal and PV systems. In the present work, high resolution irradiance data is required for the evaluation of the dynamic thermal model under intermittent cloudy conditions (see Section 4.2). For such conditions, a suitable sampling rate should be chosen that is sufficiently higher than (at least double) the highest frequency for which useful information is contained in the signal. Figures 3 and 4 show power spectral density (PSD) plots for solar irradiance data on a clear day and an intermittently cloudy day, respectively, sampled at a frequency of $1 \mathrm{~Hz}$. It is clearly noticeable that the signal intensity of the cloudy-day plot is higher than the clear-day plot for frequencies between $0.002-0.05 \mathrm{~Hz}$ (representing time-scales of 20 seconds to 10 minutes), however the majority of useful 
information is contained in the signal at frequencies lower than $0.2 \mathrm{~Hz}$. Thus in the present work, a sampling rate of $1 \mathrm{~Hz}$ for the solar irradiance measurement is considered appropriate.

(a)

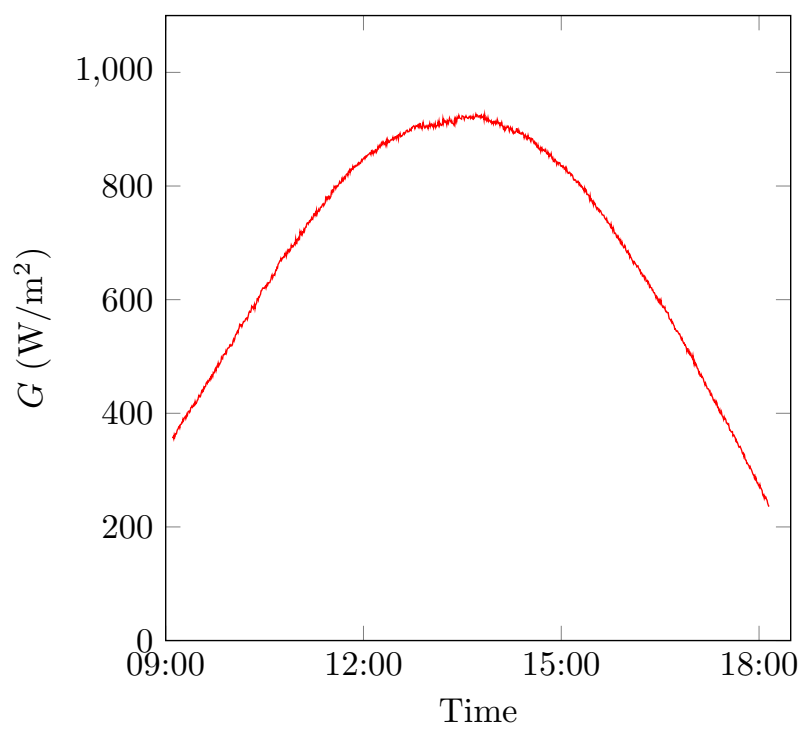

(b)

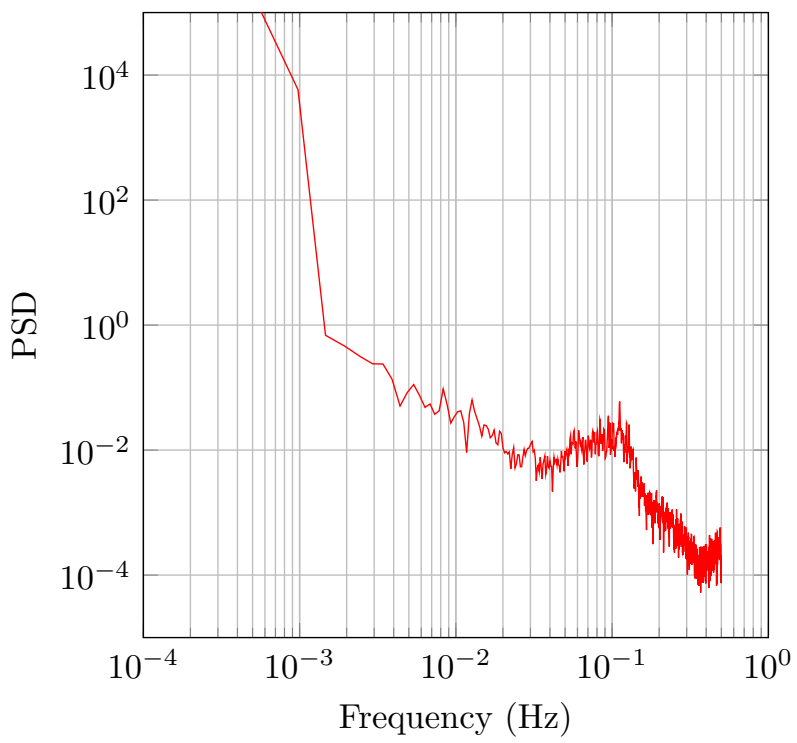

Figure 3: (a) Plot of solar irradiance against time for a clear day in June, measured at a frequency of $1 \mathrm{~Hz}$, and (b) power spectral density (PSD) plot of the solar irradiance data for the same day.

(a)

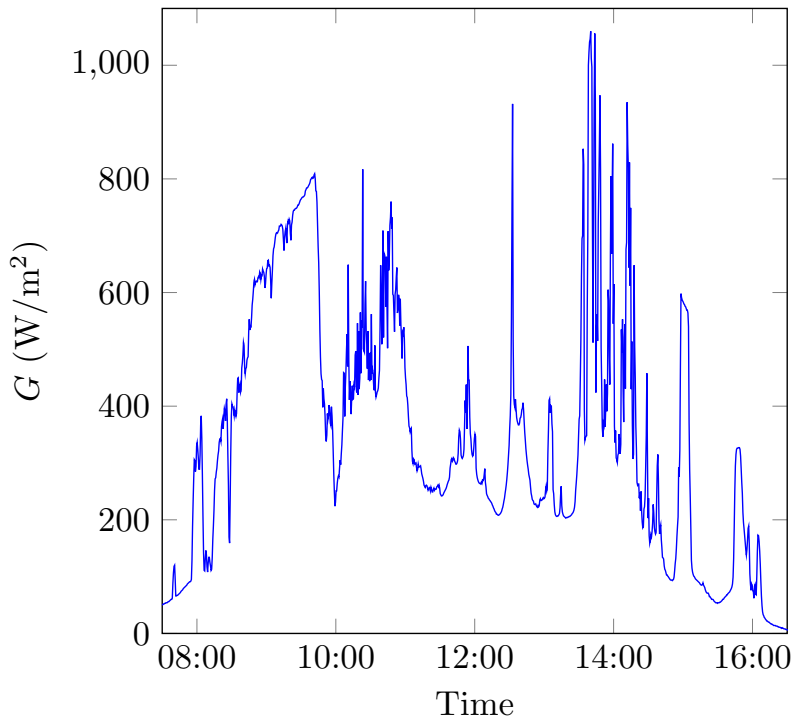

(b)

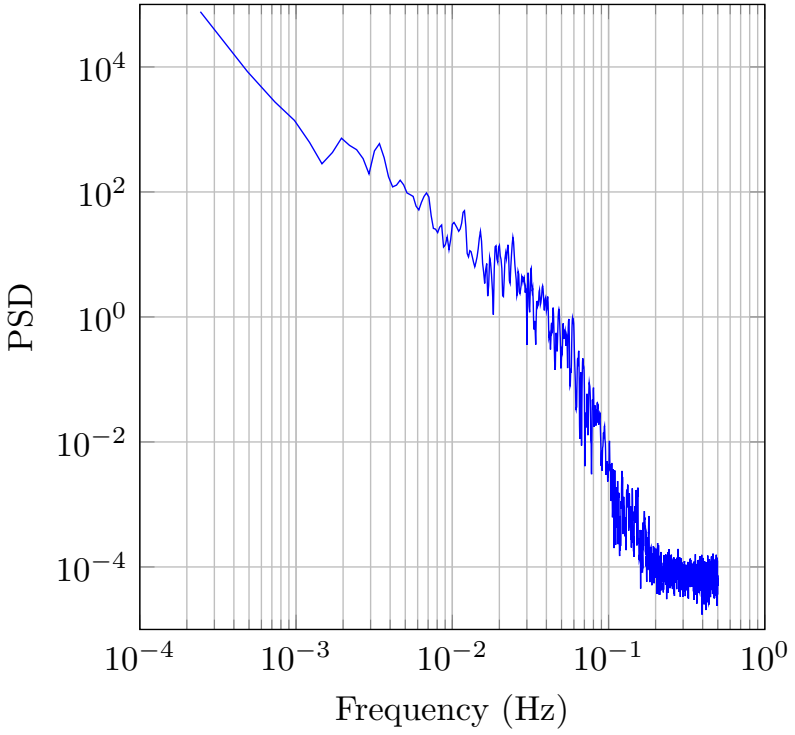

Figure 4: (a) Plot of solar irradiance against time for an intermittently cloudy day in November, measured at a frequency of $1 \mathrm{~Hz}$, and (b) power spectral density (PSD) plot of the solar irradiance data for the same day. 
Table 1: Manufacturer's specifications for the commercial PVT module M1 [23], and the solar-thermal collector, PV thin film module and glass layer used for collectors M2U, M2G and M3 [24, 25].

\begin{tabular}{llll}
\hline & PVT & FPC & PV module \\
& $(\mathrm{M} 1)$ & $(\mathrm{M} 2, \mathrm{M} 3)$ & 0.94 \\
\hline Gross area, ${ }^{2}$ & 1.42 & 1.56 & - \\
No. riser tubes, - & 14 & 7 & - \\
Tube diameter, mm & 8 & 15 & - \\
$\eta_{\mathrm{o}},-$ & 0.49 & 0.62 & - \\
$a_{1}, \mathrm{~W} /\left(\mathrm{m}^{2} \mathrm{~K}\right)$ & 4.03 & 4.24 & - \\
$a_{1}, \mathrm{~W} /\left(\mathrm{m}^{2} \mathrm{~K}\right)$ & 0.07 & 0.01 & - \\
$C, \mathrm{~kJ} \mathrm{~K}^{-1}$ & 20.0 & 14.6 & - \\
$\tau_{\mathrm{g}}(\theta=0),-$ & $\mathrm{N} / \mathrm{A}$ & 0.95 & 0.117 \\
$\eta_{\mathrm{E}, 0},-$ & 0.126 & - & -0.0038 \\
$\beta, \mathrm{K}-1$ & $\mathrm{~N} / \mathrm{A}$ & - & 93.3 \\
$V_{\mathrm{oc}}, \mathrm{V}$ & 43.4 & - & 1.7 \\
$I_{\mathrm{sc}}, \mathrm{A}$ & 5.5 & - & 110 \\
$P_{\mathrm{E}}(\mathrm{peak}, \mathrm{MPP}), \mathrm{W}$ & 180 & - & \\
\hline
\end{tabular}

The solar collector specifications are presented in Table 1. The commercial PVT collector M1 is a Solimpeks Volther Powertherm, with a $150 \mathrm{~W}_{\text {peak }}$ mono-crystalline silicon (c-Si) PV module. The thermal absorber consists of a copper sheet in contact with the rear side of the PV layer which conducts heat to the circulating fluid flowing in 14 parallel riser tubes that run vertically between the inlet and outlet header pipes.

Collectors $\mathrm{M} 2 \mathrm{U}, \mathrm{M} 2 \mathrm{G}$ and M3 were constructed in-house from a commercial flat plate collector (FPC) and a glass-encapsulated copper indium gallium selenide (CIGS) thin-film PV module. The glazing layer of the FPC was removed and the PV module was placed on top, in direct contact with the copper absorber plate. Due to its smaller area, the PV module area in contact with the absorber covered approximately $60 \%$ of the total FPC, leaving an exposed strip of thermal absorber around the edges of the PV module. To make the situation more representative in terms of thermal performance of a commercial PVT collector with a larger PV covering factor (CF), an opaque reflective material (aluminium foil with insulation) was used to shade some of the exposed absorber so that only the area at the top of the panel remained directly exposed to solar radiation (see Fig. 1b). This resulted in an increased overall covering factor of $65 \%$ for collectors $\mathrm{M} 2 \mathrm{U}$ and M2G. For collector M3, the absorber area at the top of the panel was also covered with reflective material to give a $100 \%$ covering factor, as shown in Fig. 1c For collectors $\mathrm{M} 2 \mathrm{G}$ and $\mathrm{M} 3$, the original glazing layer from the FPC was reinstalled after the addition of the PV module, while for M2U the glazed layer was left off. 


\subsection{Steady-state collector characterisation}

The procedure followed for the steady-state characterisation tests was based on the methodology described in the European Standard EN 12975-2 [8]. As the tests were performed outdoors, a certain amount of variability in the climatic conditions are expected. The minimum requirement specified in EN 12975-2 is to generate performance data over the operating temperature range of the collector under a single global irradiance condition $\geq 700 \mathrm{~W} / \mathrm{m}^{2}$ on the collector plane (although some manufacturers choose to publish test data over a wider range of irradiance levels). It is specified in the standard that irradiance should not vary by more than $\pm 50 \mathrm{~W} / \mathrm{m}^{2}$ during each measurement period, and that the incidence angle modifier of the collector should not vary by more that $\pm 2 \%$ from its normal-incidence value (normally corresponding to incidence angles in the range $0-20^{\circ}$ ). During the measurement of the thermal efficiency, the PVT electrical output was maintained at the maximum power point. It is generally recommended that the flow-rate should be set to a value close to the nominal flow-rate specified by the manufacturer. If a flow-rate is not specified, as was the case for the collectors in the present study, then a value of $0.02 \mathrm{~kg} \mathrm{~s}^{-1} \pm 10 \%$ is advised in EN 12975-2. Over a single measurement period the flow-rate should not vary by more than $\pm 1 \%$. The steady-state thermal efficiency is calculated from the experimental data using Eq. 1

$$
\eta_{\mathrm{TH}}=\frac{\dot{m} c\left(T_{\mathrm{f}-\mathrm{o}}-T_{\mathrm{f}-\mathrm{i}}\right)}{G A} .
$$

Following the procedure in EN 12975-2, a non-linear least squares fit is applied to the data so that:

$$
\eta_{\mathrm{TH}}=\eta_{\mathrm{o}}-a_{1} T^{*}-a_{2} G T^{* 2}
$$

where $T^{*}$ is the reduced mean temperature $T^{*}=\left(\bar{T}_{\mathrm{c}}-T_{\mathrm{a}}\right) / G$, and $\eta_{\mathrm{o}}, a_{1}$ and $a_{2}$ are the coefficients obtained from the fitting procedure. The mean collector temperature $\bar{T}_{\mathrm{c}}$ is taken as the linear average of the inlet and outlet fluid temperatures, $T_{\mathrm{f}-\mathrm{i}}$ and $T_{\mathrm{f}-\mathrm{o}}$.

\subsection{Dynamic collector characterisation}

The dynamic behaviour of a solar-thermal collector under time-varying environmental conditions is described using Eq. 5 .

$$
\dot{m} c\left(T_{\mathrm{f}-\mathrm{o}}-T_{\mathrm{f}-\mathrm{i}}\right)=\eta_{\mathrm{o}} A G-a_{1} A\left(\bar{T}_{\mathrm{c}}-T_{\mathrm{a}}\right)-a_{2} A\left(\bar{T}_{\mathrm{c}}-T_{\mathrm{a}}\right)^{2}-C \frac{\mathrm{d} \bar{T}_{\mathrm{c}}}{\mathrm{d} t}
$$

In this equation, the total effective heat capacity of the collector is represented by a single lumped parameter, $C$, which allows a simplified approach to transient modelling by a modification of the steady-state efficiency equation to include a single time-derivative term.

A method for estimating $C$ is presented in EN 12975-2, in which the thermal capacity of each component of the collector is multiplied by a weighting factor $p$ that describes the degree of thermal interaction it has with the circulating fluid. In the latter method, only the thermal capacity of certain components constituting 
the collector are included in the calculation, based on their estimated degree of thermal interaction with the heat transfer fluid. Thus the metal absorber is designated a high weighting factor, while the insulation and external glazing layer are designated low weighting factors. The total effective thermal capacity of the collector is found by summing the values for each element:

$$
C_{\mathrm{wt}}=\sum_{i=1}^{n} p_{i} m_{i} c_{i} .
$$

Recommended weighting factors are provided in EN 12975-2, only for a simple example of a glazed flat plate collector which includes the absorber, insulation, glazing and heat transfer fluid. Component weightings applying to other collector designs (for example the PV module for a PVT collector) are not provided in the standard.

An experimental method for evaluating $C$ is also presented in EN 12975-2. In this method, the collector is exposed to a step-change in irradiance and the time taken for the collector outlet temperature to reach a new steady-state value is measured (while the inlet temperature is maintained at a constant value). The collector is shielded with a reflective cover, while heat transfer fluid is circulated through the collector until the initial steady-state temperature is reached. The cover is removed at time $t_{1}$, exposing the collector to irradiance, and the outlet temperature monitored until a new steady state is reached at time $t_{2}$. In order to obtain the estimate of $C$ from the experimental result, first Eq. 3 is simplified to a linear function of the temperature difference between the collector and the surroundings:

$$
\dot{m} c\left(T_{\mathrm{f}-\mathrm{o}}-T_{\mathrm{f}-\mathrm{i}}\right)=\eta_{\mathrm{o}} A G-U A\left(\bar{T}_{\mathrm{c}}-T_{\mathrm{a}}\right)-C \frac{\mathrm{d} \bar{T}_{\mathrm{c}}}{\mathrm{d} t},
$$

where the heat loss coefficient $U A$ can be estimated as the gradient of useful heat output with collector temperature $-\Delta \dot{Q} / \Delta \bar{T}_{\mathrm{c}}$ under steady state conditions. Then, by integrating and rearranging Eq. 5 , the following expression is obtained:

$$
C_{\exp }=\frac{A \eta_{\mathrm{o}} \int_{\mathrm{t} 1}^{\mathrm{t} 2} G \mathrm{~d} t-\dot{m} c \int_{\mathrm{t} 1}^{\mathrm{t} 2} \Delta T_{\mathrm{f}} \mathrm{d} t-U A\left[\int_{\mathrm{t} 1}^{\mathrm{t} 2}\left(T_{\mathrm{f}-\mathrm{i}}-T_{\mathrm{a}}\right) \mathrm{d} t+0.5 \int_{\mathrm{t} 1}^{\mathrm{t} 2} \Delta T_{\mathrm{f}} \mathrm{d} t\right]}{\bar{T}_{\mathrm{c}, 2}-\bar{T}_{\mathrm{c}, 1}} .
$$

The time constant $\tau_{\mathrm{s}}$ of the dynamic response of the collector to the step-change in irradiance is evaluated as follows:

$$
\frac{T_{\mathrm{f}-\mathrm{o}}\left(t=\tau_{\mathrm{s}}\right)-T_{\mathrm{f}-\mathrm{o}}\left(t=t_{1}\right)}{T_{\mathrm{f}-\mathrm{o}}\left(t=t_{2}\right)-T_{\mathrm{f}-\mathrm{o}}\left(t=t_{1}\right)}=1-e^{-1}
$$

\subsection{Electrical efficiency}

The electrical efficiency is evaluated by measuring the electrical power at the maximum power point (MPP) across the operating temperature range of the module. The decrease in electrical efficiency with increasing module temperature is described in Refs [26-31] using the following equation:

$$
\eta_{\mathrm{E}}=\eta_{\mathrm{E}, 0}\left[1-\beta\left(T_{\mathrm{PV}}-T_{0}\right)\right]
$$


where $T_{\mathrm{PV}}$ is the $\mathrm{PV}$ temperature, $\beta$ the temperature coefficient (typically around $\sim 0.004 \mathrm{~K}^{-1}$ for c-Si cells), and $\eta_{\mathrm{E}, 0}$ is the electrical efficiency at the reference temperature $T_{0}=298 \mathrm{~K}$. In the present work, for cases where a direct measure of the PV cell temperature is not available the mean fluid temperature will be used instead:

$$
\eta_{\mathrm{E}}=\eta_{\mathrm{E}, 0}\left[1-\beta^{*}\left(\bar{T}_{\mathrm{c}}-T_{0}\right)\right]
$$

The electrical efficiency can be corrected for the effect of decreased glass transmittance at non-perpendicular incidence angles using the following equation:

$$
\eta_{\mathrm{E}}^{*}=\frac{\eta_{\mathrm{E}}}{\tau_{\mathrm{g}}(\theta)},
$$

where $\eta_{\mathrm{E}}{ }^{*}$ is the electrical efficiency that would be expected for a perpendicular incidence angle.

\subsection{3-D dynamic PVT collector model}

In addition to the performance characterisation exercises described above, the experimental data collected in the steady-state and dynamic tests will be used to validate a detailed three-dimensional (3-D) numerical model of a sheet-and-tube PVT collector developed in earlier work. The model will be configured using the known geometrical and material parameters of the PVT collectors investigated in this study, and simulations will be performed using the high-resolution solar irradiance and ambient temperature data collected during the tests. The predictions of the 3-D model will be compared to the real electrical and thermal performance data from the tests, and to predictions from a zero-dimensional (0-D) lumped PVT collector model based on the parameters $\eta_{\mathrm{o}}, a_{1}, a_{2}$ and $C$. The relative merits of the two modelling approaches will be discussed.

The main energy balance equations used in the 3-D model are summarised below. For the full list of equations, and further details of the heat transfer coefficients, optical properties and model assumptions the reader is referred to Ref. [7].

$$
\begin{aligned}
m_{\mathrm{g}} c_{\mathrm{g}} \frac{\mathrm{d} T_{\mathrm{g}}}{\mathrm{d} t}= & \dot{Q}_{\mathrm{g}-\mathrm{CD}(x, y)}-A_{x y} \epsilon_{\mathrm{g}} \sigma\left(T_{\mathrm{g}}^{4}-T_{\mathrm{sky}}^{4}\right)-A_{x y} h_{\mathrm{top}}\left(T_{\mathrm{g}}-T_{\mathrm{a}}\right) \\
& +A_{x y} \sigma \frac{\left(T_{\mathrm{PV}}^{4}-T_{\mathrm{g}}^{4}\right)}{\frac{1}{\epsilon_{\mathrm{g}}}+\frac{1}{\epsilon_{\mathrm{PV}}}-1}+A_{x y} h_{\mathrm{gap}}\left(T_{\mathrm{PV}}-T_{\mathrm{g}}\right)+\alpha_{\mathrm{g}} G ; \\
m_{\mathrm{PV}} c_{\mathrm{PV}} \frac{\mathrm{d} T_{\mathrm{PV}}}{\mathrm{d} t}= & \dot{Q}_{\mathrm{PV}-\mathrm{CD}(x, y)}-A_{x y} \sigma \frac{\left(T_{\mathrm{PV}}^{4}-T_{\mathrm{g}}^{4}\right)}{\frac{1}{\epsilon_{\mathrm{g}}}+\frac{1}{\epsilon_{\mathrm{PV}}}-1}-A_{x y} h_{\mathrm{gap}}\left(T_{\mathrm{PV}}-T_{\mathrm{g}}\right) \\
& -\frac{A_{x y}}{R_{\mathrm{PV}}}\left(T_{\mathrm{PV}}-T_{\mathrm{AB}}\right)+\overline{\tau \alpha}_{\mathrm{PV}} G-P_{\mathrm{E}, x y} ; \\
m_{\mathrm{AB}} c_{\mathrm{AB}} \frac{\mathrm{d} T_{\mathrm{AB}}}{\mathrm{d} t}= & \dot{Q}_{\mathrm{AB}-\mathrm{CD}(x, y)}+\frac{A_{x y}}{R_{\mathrm{PV}}}\left(T_{\mathrm{PV}}-T_{\mathrm{AB}}\right)-A_{\mathrm{b}} \frac{k_{\mathrm{b}}}{\delta_{\mathrm{b}}}\left(T_{\mathrm{AB}}-T_{\mathrm{p}}\right) \\
& -\frac{A_{x y}}{R_{\mathrm{loss}}}\left(T_{\mathrm{AB}}-T_{\mathrm{a}}\right) ;
\end{aligned}
$$




$$
\begin{gathered}
m_{\mathrm{p}} c_{\mathrm{p}} \frac{\mathrm{d} T_{\mathrm{p}}}{\mathrm{d} t}=\dot{Q}_{\mathrm{p}-\mathrm{CD}(y)}+A_{\mathrm{b}} \frac{k_{\mathrm{b}}}{\delta_{\mathrm{b}}}\left(T_{\mathrm{AB}}-T_{\mathrm{p}}\right)-\pi D h_{\mathrm{f}} \mathrm{d} y\left(T_{\mathrm{p}}-T_{\mathrm{f}}\right) ; \\
m_{\mathrm{f}} c_{\mathrm{f}} \frac{\mathrm{d} T_{\mathrm{f}}}{\mathrm{d} t}=\pi D h_{\mathrm{f}} \mathrm{d} y\left(T_{\mathrm{p}}-T_{\mathrm{f}}\right)+\dot{m} c_{\mathrm{f}} \frac{\mathrm{d} T_{\mathrm{f}}}{\mathrm{d} y}
\end{gathered}
$$

Equation 11 is the energy balance for the glass cover which considers conduction between adjacent nodes in the $x-y$ plane, radiative losses to the sky, convective losses to ambient air, convective and radiative heat transfer between the glass and the PV module, and the fraction of incident irradiance absorbed as heat by the glass cover. Equation. 12 is the energy balance for the PV module which considers both radiative and convective heat losses to the glass, conduction to the copper absorber (described with the thermal resistance $R_{\mathrm{PV}}$ ), and the fraction of irradiance absorbed as heat by the PV module, minus that converted to electrical power $P_{\mathrm{E}}$. Equation 13 is the energy balance at the copper absorber sheet, which considers the heat conducted to the absorber from the hotter PV layer, heat conducted from the absorber to the pipe, and heat lost to the environment by conduction through the rear insulation followed by convection to the ambient air (described using the combined thermal resistance $R_{\text {loss }}$ ). Equation 14 is the energy balance for the pipe which considers conduction from the absorber, conduction along the pipe in the flow direction $y$, and convective heat transfer to the fluid. Equation 15 is the energy balance at the fluid node, which describes the convective heat transfer between the pipe wall and the fluid, and the enthalpy rise of the fluid between each node in the flow direction.

\section{Characterisation test results}

In this section, results are reported from the steady-state and dynamic tests performed on the PVT collectors. The thermal performance tests with collector M1 were performed at AELab in Nicosia [18, while all other tests were performed at the Cyprus University of Technology in Limassol. The results of the former tests are reported with a lower degree of uncertainty (shown by smaller error bars) due to improved sensor calibration capabilities and the use of higher accuracy instruments and measuring devices.

\subsection{Steady-state test results}

\subsubsection{Thermal efficiency variation with electrical load}

The thermal efficiency of M1 was evaluated for two operating modes: (i) open circuit (no electrical load connected) and (ii) with an electrical load connected and generating power close to the maximum power point (MPP). It is recommended that inverters with embedded power point tracking devices are used for accurate steady-state electrical and thermal characterisation of PVT collectors. The thermal efficiency is higher when the PVT collector operates in open circuit because $\sim 11 \%$ more energy is available for thermal conversion. On the other hand, the heat losses are increased because the fluid reaches a higher temperature. 


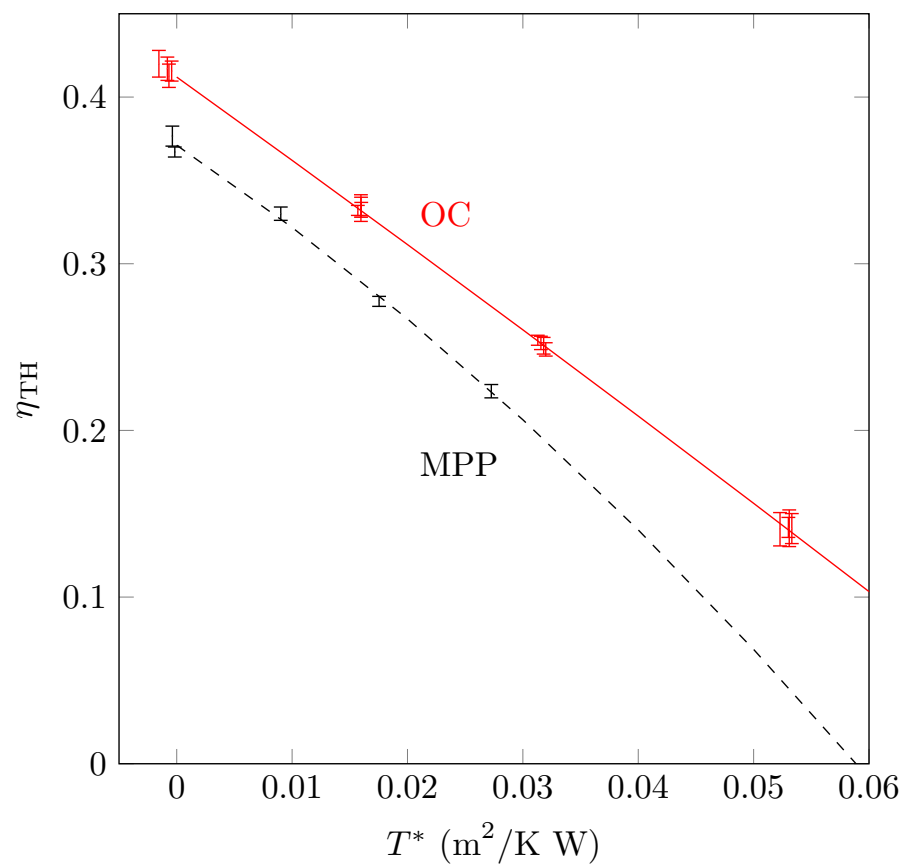

Figure 5: Thermal efficiency curves for PVT collector M1 in maximum power point (MPP) mode (black dashed line) and open circuit (OC) mode (red solid line).

The collector efficiency curve for the two operating modes of M1 is shown in Fig. 5, where the thermal efficiency is plotted against the reduced mean temperature $T^{*}$. The efficiency curve coefficients obtained from a fit of the experimental data are reported in Table 2

\subsubsection{Thermal and electrical efficiency with glass cover}

The glazed and unglazed PVT collectors M2G and M2U were tested under outdoor conditions in Limassol during the month of July. Solar irradiance measured at the tilted plane of the collector was found to vary in the range $650-910 \mathrm{~W} / \mathrm{m}^{2}$ during the tests. The fluid temperature at the collector inlet was varied over a range typical of domestic hot water applications, between $32-76{ }^{\circ} \mathrm{C}$. Plots of collector efficiency curves over

Table 2: Thermal efficiency curve coefficients determined from the steady-state tests of PVT modules M1 (commercial glazed module), and M2 (glazed and unglazed variants), with test conditions in the following ranges: $G=670-910 \mathrm{~W} / \mathrm{m}^{2} ; T_{\mathrm{a}}=38-$ $39{ }^{\circ} \mathrm{C} ; T_{\mathrm{f}-\mathrm{i}}=32-76{ }^{\circ} \mathrm{C}$. PVT module M1 is tested with the PV operating both in open circuit and at the maximum power point (MPP).

\begin{tabular}{lccc}
\hline PVT module & $\begin{array}{c}\eta_{\mathrm{o}} \\
(-)\end{array}$ & $\begin{array}{c}a_{1} \\
\left(\mathrm{~m}^{2} \mathrm{~K} / \mathrm{W}\right)\end{array}$ & $\begin{array}{c}a_{2} \\
\left(\mathrm{~m}^{2} \mathrm{~K}^{2} / \mathrm{W}\right)\end{array}$ \\
\hline M1 (PV open-circuit) & 0.42 & 4.96 & 0.003 \\
M1 (PV at MPP) & 0.37 & 4.64 & 0.03 \\
M2U & 0.32 & 7.07 & 0.07 \\
M2G & 0.39 & 2.17 & 0 \\
\hline
\end{tabular}




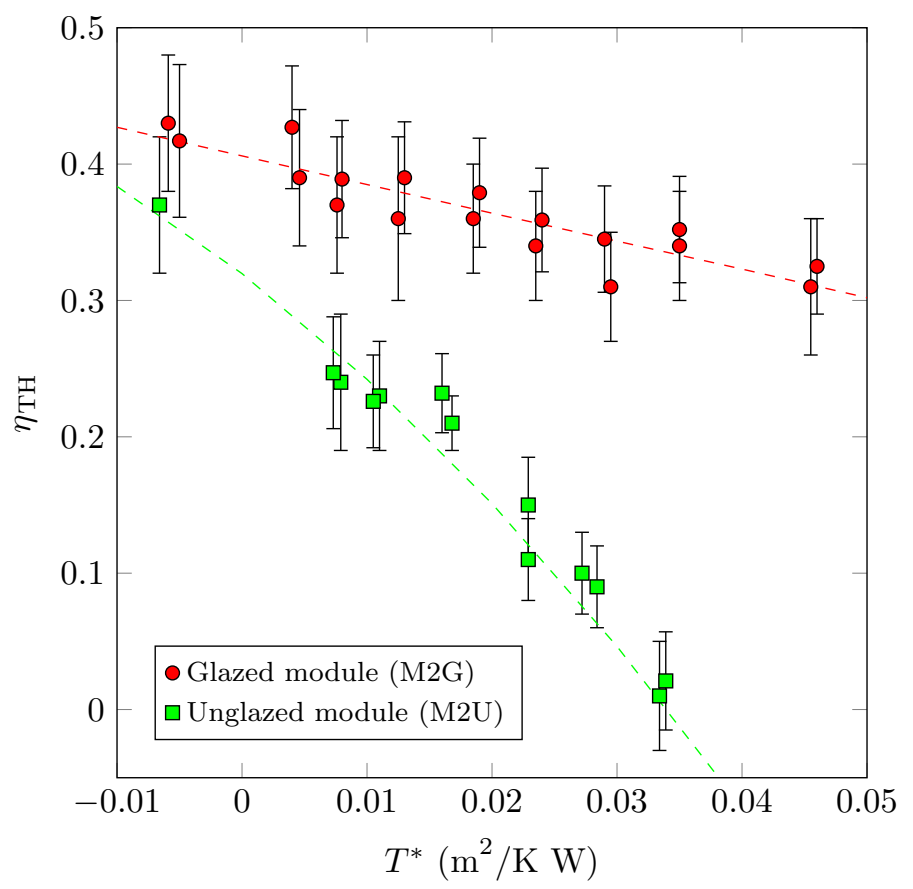

Figure 6: Thermal efficiency of $\mathrm{M} 2 \mathrm{U}$ and $\mathrm{M} 2 \mathrm{G}$ panels.

the range of $T^{*}$ values for $\mathrm{M} 2 \mathrm{U}$ and $\mathrm{M} 2 \mathrm{G}$ are shown in Fig. 6. The total uncertainty associated with the results obtained using the Limassol testing apparatus is $\sim 10 \%$ (see the Appendix section). The efficiency curve coefficients obtained from the fit of the experimental data are reported in Table 2. From these results it is evident that adding a glass layer results in an improvement in the thermal efficiency. The first-order heat loss coefficient $a_{1}$ decreases from $8.37 \mathrm{~W} / \mathrm{m}^{2} \mathrm{~K}$ for the unglazed collector M2U to $2.17 \mathrm{~W} / \mathrm{m}^{2} \mathrm{~K}$ for the glazed collector M2G. The optical (or so-called "zero-loss") efficiency $\eta_{\mathrm{o}}$ is also slightly improved for the glazed configuration despite additional optical losses due to reflection. The results show that the unglazed PVT module, due to its lower stagnation temperature, is suitable only for applications that require fluid temperatures of up to $65^{\circ} \mathrm{C}$.

The electrical efficiency of M2U decreases linearly with the mean fluid temperature as shown in Fig. 7 A linear fit through the data-points results in a gradient of $-0.0014 \mathrm{~K}^{-1}$ and a $y$-intercept of 0.066 , which are significantly different from the corresponding values $\beta=-0.0038 \mathrm{~K}^{-1}$ and $\eta_{\mathrm{E}, 0}=0.117$ stated in the manufacturer's data sheet for the PV module. It should be noted however that the manufacturer's coefficients are based on the PV cell temperature rather the mean fluid temperature.

The electrical efficiency of M2G is on average $20 \%$ lower than the electrical efficiency of M2U due to reflection and absorption losses caused by the additional cover glass. The total reflectance of the collectors can be estimated from the glass and PV optical properties using the formulations reported in Refs. [32 34]. At normal incidence the total reflectance is $12 \%$ and $10 \%$, for the glazed and unglazed collectors respectively. 


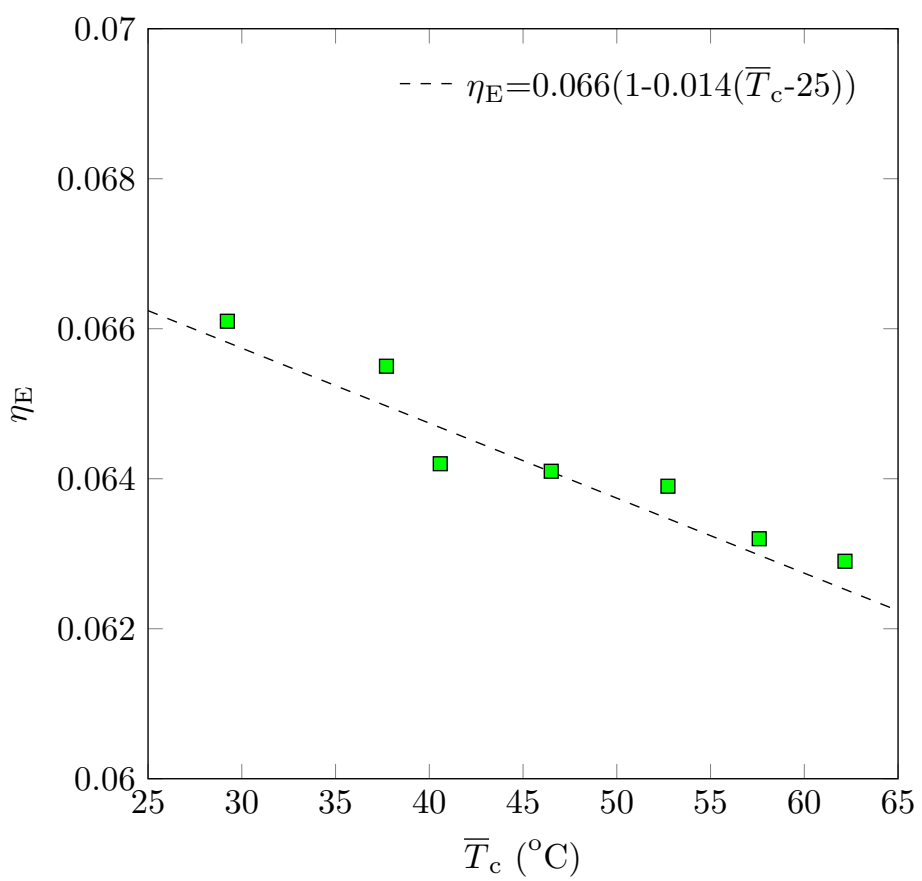

Figure 7: Temperature dependence of the electrical efficiency of the unglazed PVT module (with thin film PV). The electrical efficiency is plotted against the mean collector (fluid) temperature $\bar{T}_{\mathrm{c}}$.

However, the glass-layer transmittance is further reduced at larger incidence angles, leading to a further losses in electrical performance. Moreover, this is found to have a notable effect on the results, as shown in Fig. 8 During the hours over which the tests were performed (between 10:47 a.m. and 1:20 p.m.), the smallest incidence angle $\left(26^{\circ}\right)$ corresponds to a glass transmittance value of 0.9 , while the largest incidence angle $\left(\sim 34^{\circ}\right)$ corresponds to a lower transmittance value of 0.87 . At the lowest collector temperature, for which the electrical efficiency would ordinarily be highest, the larger incidence angle corresponds to a reduced glass transmittance (shown by the star points) and the result is a decrease in electrical efficiency (shown by the circular points). The point at which the maximum electrical efficiency occurs is due to a combination of the collector temperature and incidence angle. To show more clearly the influence of the collector temperature, the electrical efficiency is corrected for the effect of the decreased glass transmittance at non-perpendicular incidence angles using Eq. 10. The corrected results, shown by the solid triangle points in Fig. 8, show the anticipated linear trend of decreasing electrical efficiency with increasing temperature and also show good agreement with the results obtained for the unglazed collectors.

\subsubsection{Sensitivity to thermal contact}

The preferred method for manufacturing a PVT module to achieve a good thermal contact between the PV layer and the absorber is to laminate the top cover, PV layer and absorber in a single assembly while electrically insulating the PV layer at the same time. A simpler, lower-cost alternative used for some commercial 


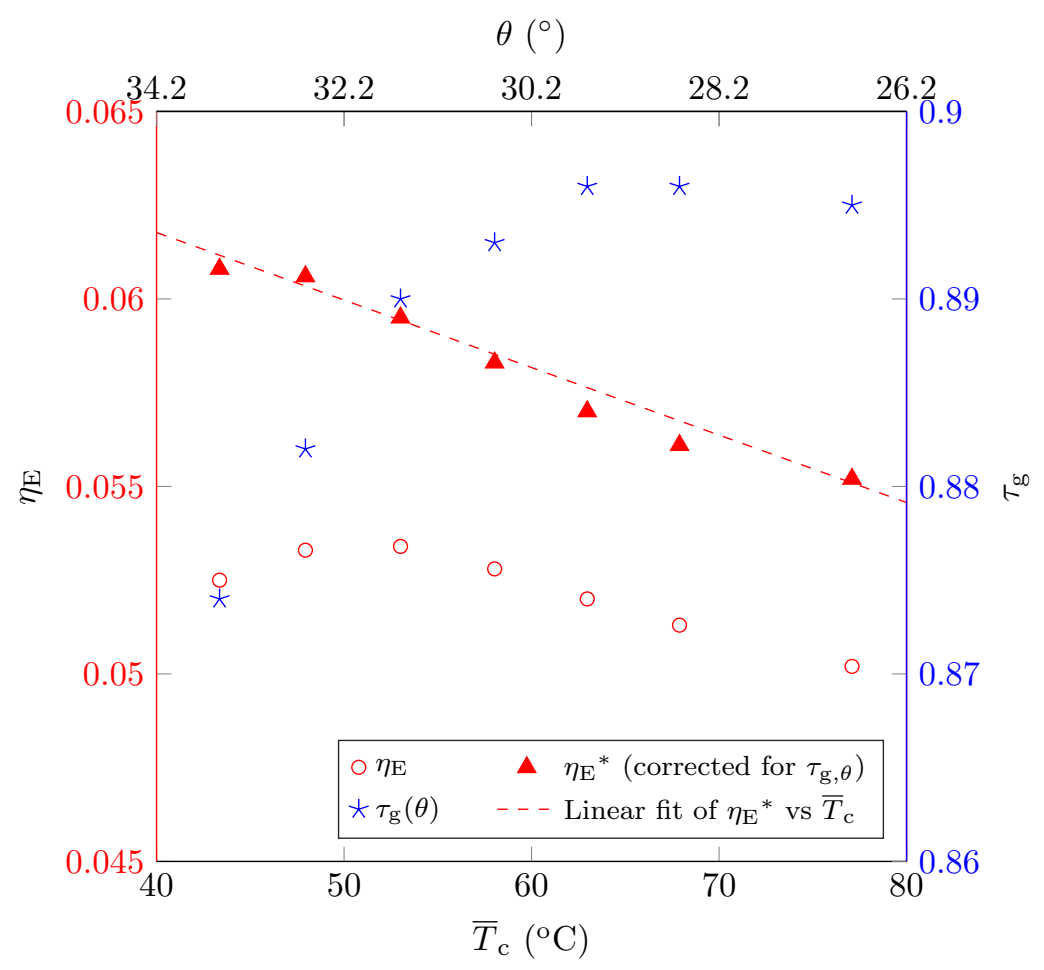

Figure 8: Electrical efficiency $\eta_{\mathrm{E}}$ of $\mathrm{M} 2 \mathrm{G}$ plotted as a function of the mean fluid temperature $\bar{T}_{\mathrm{c}}$; and transmittance of the glazed layer $\tau_{\mathrm{g}}$ plotted as a function of the corresponding solar incidence angle, which has a strong influence on $\eta_{\mathrm{E}}$. The modified electrical efficiency $\eta_{\mathrm{E}}^{*}$ is corrected for non-perpendicular incidence angle using Eq. 10 to show more clearly the influence of $\bar{T}_{\mathrm{c}}$.

PVT collectors (including collector M1) is to place the absorber in contact with the PV cell, often with a thin thermally-conductive material inbetween to provide a thermal contact (see Fig. 9). The materials are typically silicone adhesives, copper foils, aluminium filled epoxy glue and silver filled glue 35 38.

The thermal efficiency of collector M1, obtained from the experiments in Section 3.1.1 was found to be $23 \%$ lower than the values predicted from the manufacturer's efficiency curve, reported in Table 1 . The module was opened to investigate possible reasons for the poorer thermal performance and to inspect for damage. Figure 10 shows the rear side of the PV layer in collector M1 (left) and the top surface of the copper absorber fins (right). The back of the PV module was covered with a uniform layer of black thermal grease

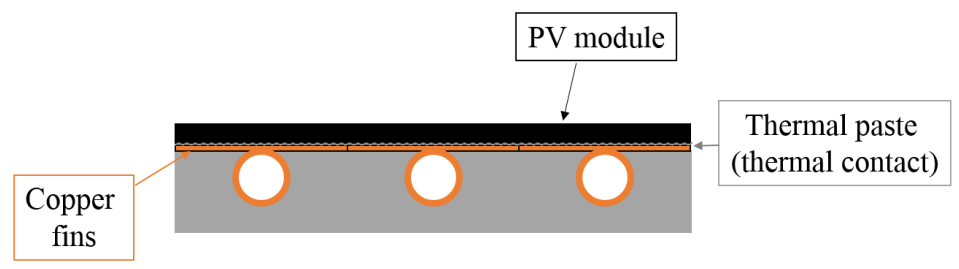

Figure 9: Schematic of a PVT module assembly including the PV module, the copper fins and pipes and the thermal grease. 

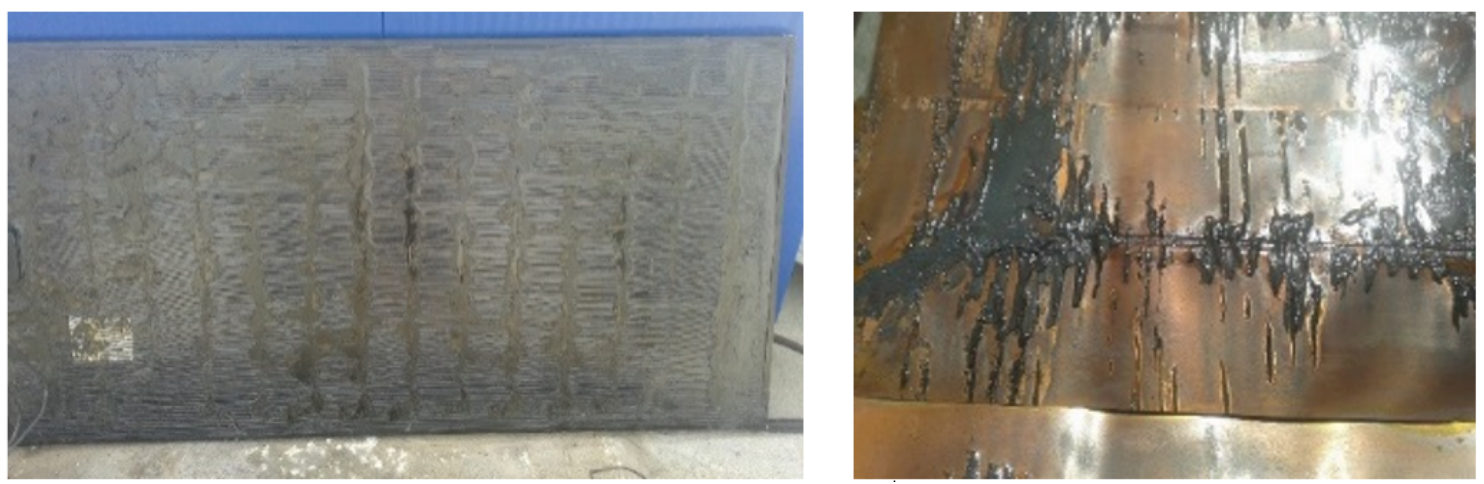

Figure 10: Detail of the material layers forming PVT collector M1. Left: the rear surface of the PV layer, covered by a uniform layer of black grease of $\sim 3 \mathrm{~mm}$ thickness. Right: the top surface of the thermal absorber layer, formed from copper fins bent around the riser tubes, with the deformation resulting in only partial contact with the PV/grease layer.

(Fig. 10, left). Although no damage was visible, the thermal contact between the PV layer and the strips of copper sheet forming the absorber fins was found to be poor. Although the thermal grease was applied uniformly to rear side of the PV layer (Fig. 10, left), this provided only a partial contact with the top surface of the absorber fins, which were deformed around the riser tubes resulting in large air gaps over much of the collector's surface area (Fig. 10, right).

For the glazed collector M2G, improvements were made to the thermal contact between the PV layer and the thermal absorber by applying a silicon paste (see Fig. 11). The thermal conductivity of the paste was $2.3 \mathrm{~W} / \mathrm{m} \mathrm{K}$ according to the manufacturer's data sheet [39. It was found that an improvement in thermal

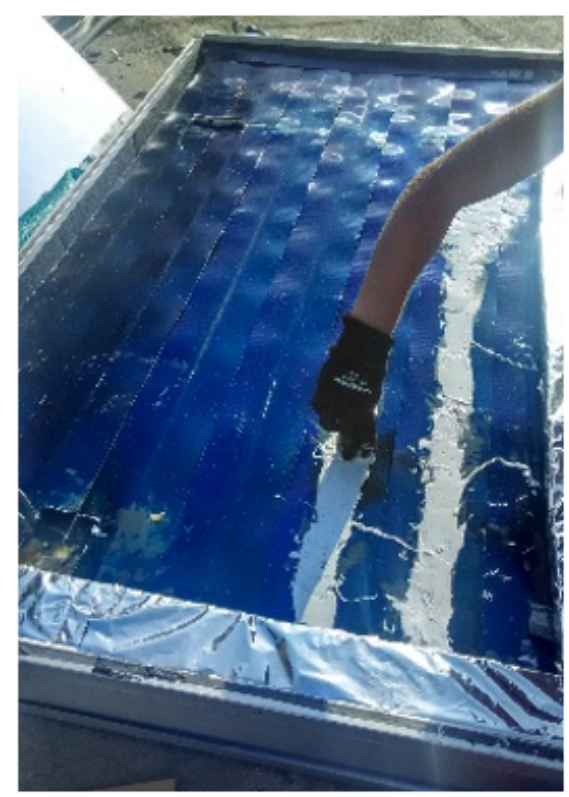

Figure 11: Application of the thermal paste on the copper fin of the thermal collector. 
(a)

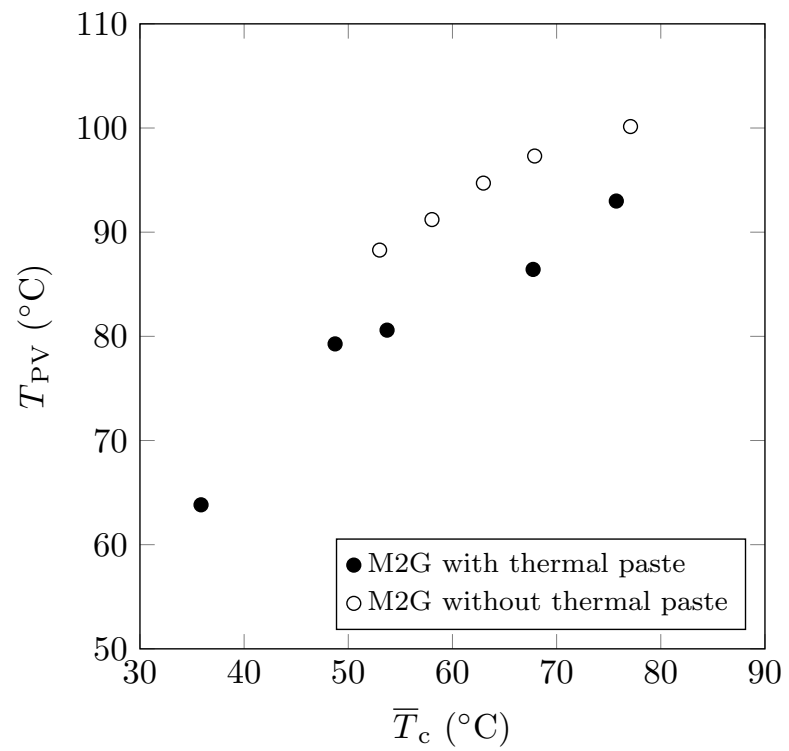

(b)

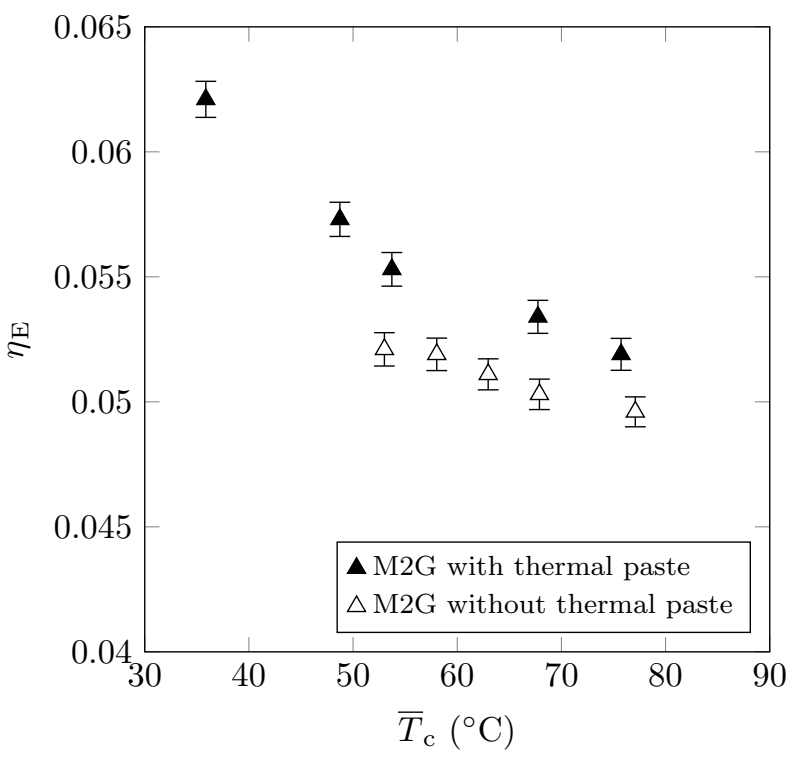

(c)

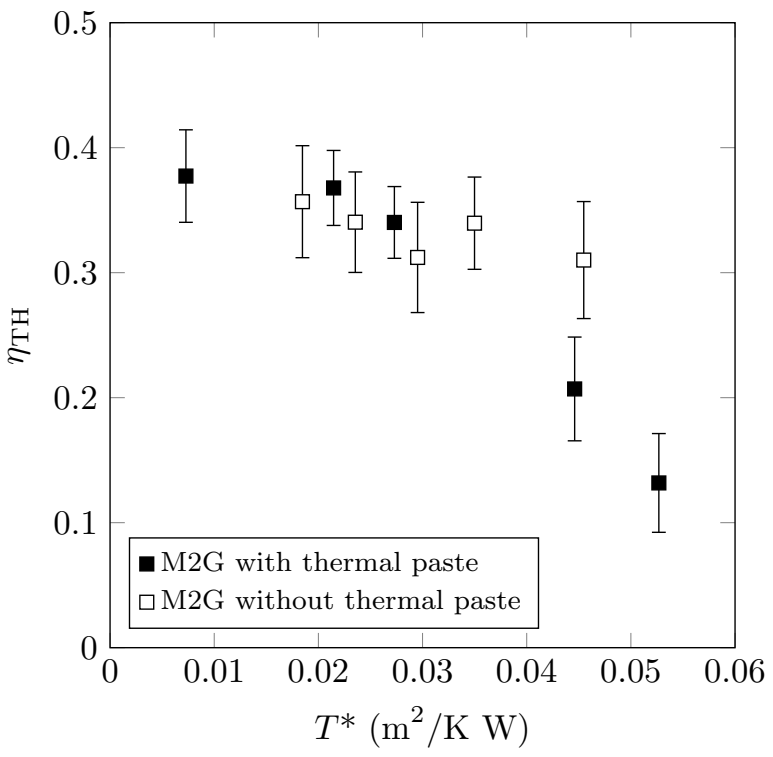

Figure 12: (a) PV temperature, (b) electrical efficiency and (c) thermal efficiency of glazed collector M2G, compared before and after the application of conductive paste to improve thermal contact between PV layer and absorber. Results shown are for test conditions in the range $G=800-900 \mathrm{~W} / \mathrm{m}^{2}$ and $T_{\mathrm{a}}=29-39{ }^{\circ} \mathrm{C}$. 


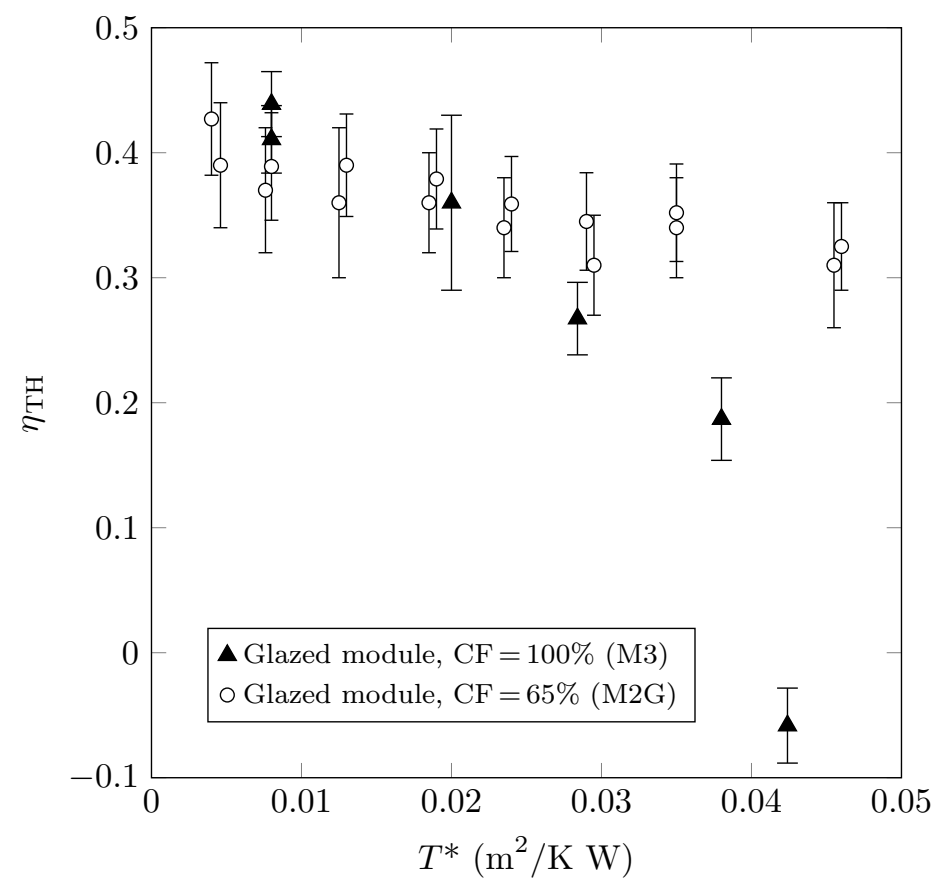

Figure 13: Comparison of the thermal efficiency of the glazed PVT module with $100 \%$ covering factor (black circles) and with $65 \%$ covering factor (white squares).

efficiency could not be observed conclusively over the range of conditions in the outdoor tests, however Fig. 12 shows that the application of the paste results in a $\sim 10{ }^{\circ} \mathrm{C}$ lower temperature measured on the $\mathrm{PV}$ layer; which in turn results in a $6-8 \%$ relative improvement in electrical efficiency, and also has the potential to bring about further benefits such as a reduced long-term performance degradation of the PV module [40.

\subsubsection{Thermal and electrical efficiency with covering factor}

For the M2G and M2U collectors, the PV module covered only $65 \%$ of the area of the thermal absorber, leaving the remaining area at the top of the collector exposed (see Fig. 1c). For collector M3, the effect on the thermal performance of having a $100 \%$ coverage area was investigated by using a reflective thermal insulator to cover the remaining exposed absorber area, thus preventing it from contributing to the useful thermal output of the collector. The thermal efficiency was then calculated based only on the area of the collector covered by the PV module.

Figure 13 shows that the thermal efficiency of M3 was similar to M2G at low values of $T^{*}$, but experienced a more pronounced deterioration at increased fluid temperatures. It should be noted that the emissivity of the PV layer is high compared with the selectively-coated copper absorber $(\sim 0.8$ compared to $\sim 0.05[41,43$ ] resulting in more significant radiative losses at higher operating temperatures from the PV layer. 


\subsubsection{Comparison of $P V$ module operation in standalone and PVT modes}

The c-Si and a-Si PV modules (used the M1 and M2 collectors, respectively) were removed from the PVT collector assembly and tested in standalone operation (without active cooling, glazing, or rear insulation). Under conditions of $G=870 \mathrm{~W} / \mathrm{m}^{2}$ and $T_{\mathrm{a}}=33^{\circ} \mathrm{C}$, and with low local wind speeds, the c-Si PV module reached a maximum temperature in standalone operation of $60{ }^{\circ} \mathrm{C}$ with a corresponding electrical efficiency of 14\%. The a-Si module meanwhile reached a maximum temperature of $42{ }^{\circ} \mathrm{C}$ with a corresponding electrical efficiency of $11.5 \%$.

By comparison, when operating in a glazed PVT configuration, the PV-layer temperatures were measured in the range $75-100{ }^{\circ} \mathrm{C}$ (see Fig. 12a). The high PV temperatures are a result of the relatively high fluid temperatures, and reduced heat losses to the environment due to the glazing and back insulation. Consequently, it is expected that the electrical efficiency a PVT collector operating in a temperature range of $40-80{ }^{\circ} \mathrm{C}$ will be lower than that of an equivalent PV module in standalone operation due to the high operating temperatures (and also due to additional optical losses for the case of a glazed PVT module).

\subsection{Dynamic testing results}

The results of the dynamic tests, along with the corresponding test conditions, are presented in Table 3 . The experimental values of the collector time constant $\tau$ and effective heat capacity $C_{\exp }$ are obtained using the methods described in Section 2.3. Also reported in the table is the alternative value for the effective heat capacity, $C_{\mathrm{wt}}$, obtained using the weighting-factor calculation method also described in Section 2.3 . The material masses and specific heat capacities used for the calculation are listed in Table 4 along with the relevant weighting factors (recommended in EN 12975-2 [8], where available). Components such as the frame and the connecting pipework upstream of the inlet temperature measurement and downstream of the outlet temperature measurement are assumed to be thermally isolated from the fluid in the collector and are not included in the calculation. Meanwhile, due to its close thermal contact with the absorber, a weighting factor of 1 is assumed for the PV module.

The temperature evolution for M1 during the dynamic test is plotted in Fig. 14. The average time constant measured for M1 was $474 \mathrm{~s} \mathrm{(} 8 \mathrm{mins}$ ), which is considerably longer than the $90 \mathrm{~s}$ average time constant measured for the glazed module M2G. In general a longer time constant corresponded to a larger effective heat capacity, however this was not always the case among repeat tests, because the increase in outlet temperature did not always follow a smooth exponential rise to a new steady state. M1 was found to have the largest effective heat capacity and time constant of all the collectors tested, due to certain design and construction features such as the flow-rate restriction imposed by the small diameter of the riser tubes and the poor thermal contact between the PV and thermal absorber layers, discussed in Section 3.1.3.

For all collectors, there is a large difference between the experimentally-obtained values of the effective heat capacity $C_{\exp }$, and the values obtained using the calculation-based method $C_{\mathrm{wt}}$ which is generally found 


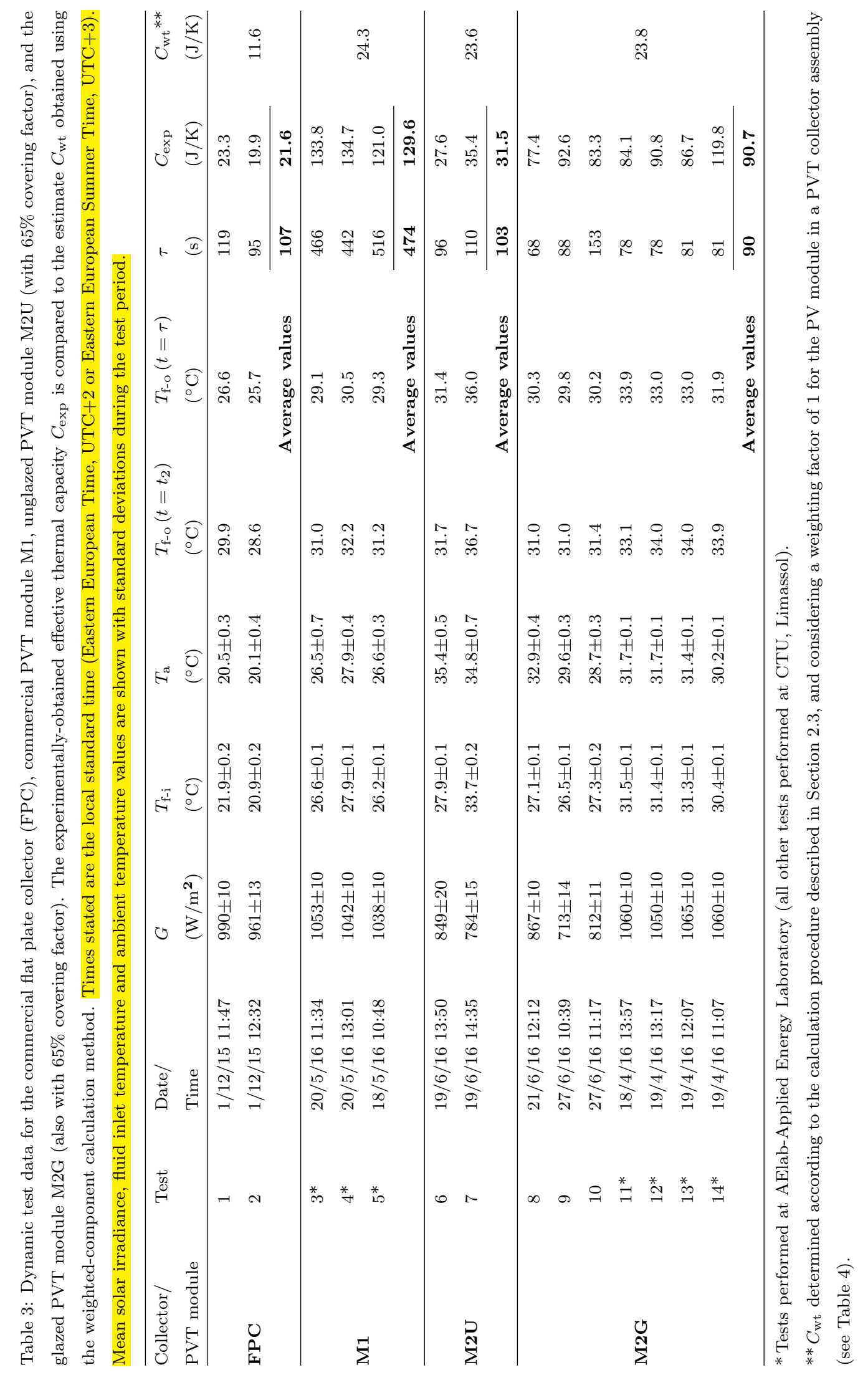


Table 4: Component material properties and weighting factors (according to EN 12975-2) for the PVT collector M1, and for the solar-thermal collector and thin film CIGS module used to construct the glazed and unglazed PVT collectors M2G, M2U and M3.

\begin{tabular}{|c|c|c|c|c|c|c|}
\hline & Material(s) & $\begin{array}{l}\rho \\
\left(\mathrm{kg} / \mathrm{m}^{3}\right)\end{array}$ & $\begin{array}{l}m \\
(\mathrm{~kg})\end{array}$ & $\begin{array}{l}c_{\mathrm{p}} \\
(\mathrm{J} / \mathrm{kg} \mathrm{K})\end{array}$ & $\begin{array}{l}m c \\
(\mathrm{~J} / \mathrm{K})\end{array}$ & $\begin{array}{l}p \\
(-)\end{array}$ \\
\hline \multicolumn{7}{|l|}{ PVT (M1) } \\
\hline Absorber plate \& tubing & Copper & 8980 & 2.6 & 390 & 990 & 1 \\
\hline Glass cover & Glass & 2700 & 12.7 & 800 & 10,170 & 0.014 \\
\hline Fluid & Water & 1000 & 0.5 & 4190 & 2200 & 1 \\
\hline Insulation & EPS, glass wool & - & 1.7 & 980 & 1670 & 0.5 \\
\hline PV module & & - & 15.8 & - & 20,110 & 1 \\
\hline \multicolumn{7}{|l|}{ FPC (M2, M3) } \\
\hline Absorber plate \& tubing & Copper & 8980 & 7.1 & 385 & 2750 & 1 \\
\hline Glass cover & Glass & 2700 & 15.6 & 800 & 12,460 & 0.014 \\
\hline Fluid & Water & 1000 & 1.8 & 4190 & 7720 & 1 \\
\hline Insulation & EPS & 18 & 0.6 & 1300 & 1800 & 0.5 \\
\hline Insulation & Glass wool & 24 & 1.6 & 670 & 1090 & 0.5 \\
\hline \multicolumn{7}{|l|}{ PV module (M2, M3) } \\
\hline Thin-film PV module & Glass & 2700 & 16.5 & 800 & 12,170 & 1 \\
\hline
\end{tabular}

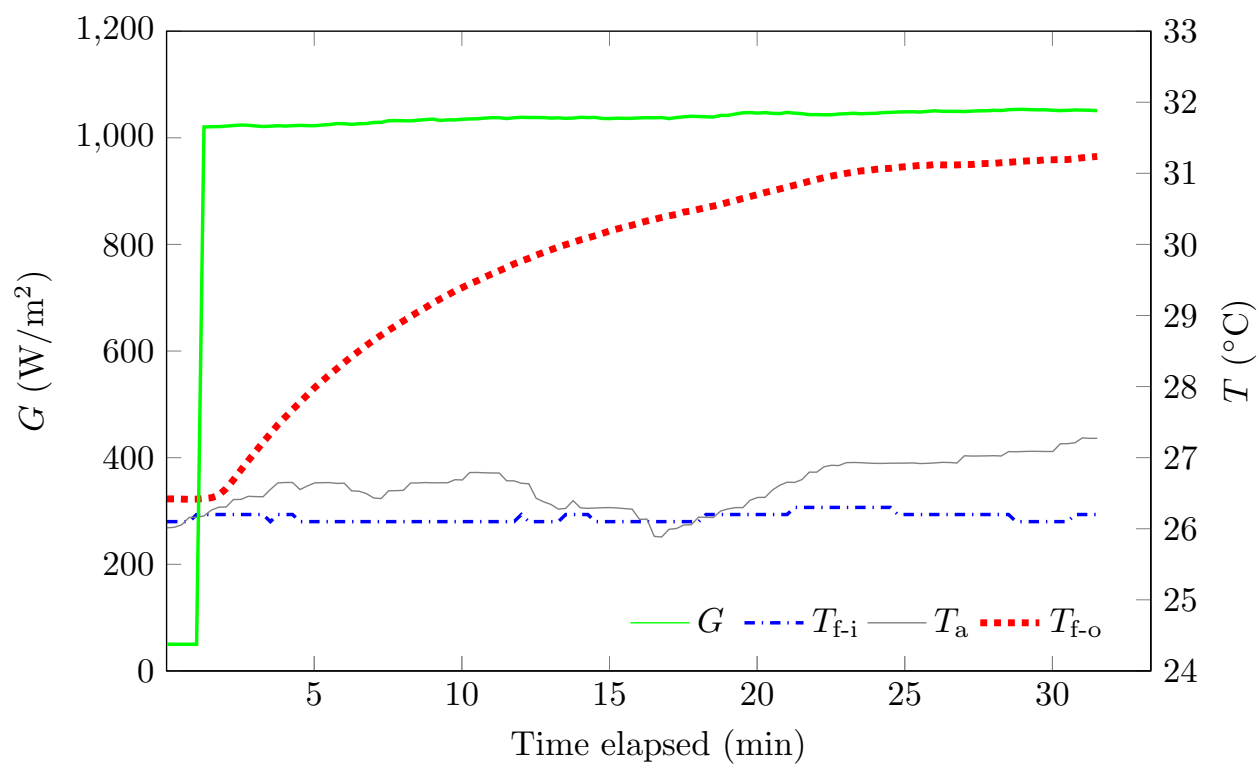

Figure 14: Test 3, dynamic test of commercial PVT module M1. During the test, the collector inlet temperature is maintained close to the ambient temperature. The collector is initially shaded with a reflective cover, then exposed to a step change in irradiance by removing the cover, while the response of the collector outlet temperature is measured. 
to be 2 to 5 times smaller. The experimental values were sensitive to environmental conditions and flow-rate, and repeatability was difficult to achieve. Moreover, the time taken for the PVT collectors to reach a new steady state when exposed to an irradiance step-change was as much as $30 \mathrm{~min}$; far longer than that for the flat plate thermal collector. This suggests that dynamic testing of PVT collectors is likely to be a slow and expensive process, and that an accurate predictive model may be useful as a cost-effective alternative.

\section{Diurnal performance}

In this section, electrical and thermal performance data are presented for the various PVT collectors, monitored over a diurnal operating period. Each collector is operated at constant flow-rate for the duration of the test, while the thermal energy collected is stored in the hot water tank. At the end of the monitoring period the total electricity generated and thermal energy accumulated in the storage tank are evaluated, as well as the daily-averaged electrical and thermal efficiencies. The daily performance results and the range of operating conditions are reported in Table 5 . For each test, the monitoring period is started at the same time in the morning (10:15 local time), and stopped at the end of the day when the thermal efficiency of the the collector falls below zero.

\subsection{Thermal energy generation}

The results reported in Table 5 show that for the unglazed PVT collector M2U a lower amount of thermal energy $\left(2.0 \mathrm{kWh}_{\mathrm{th}}\right)$ is stored over the daily operating period than for the two glazed modules $\left(2.2-2.7 \mathrm{kWh}_{\mathrm{th}}\right.$ for $\mathrm{M} 1$ and $2.5-3.3 \mathrm{kWh}_{\mathrm{th}}$ for $\mathrm{M} 2 \mathrm{G}$ ). When the collector area and daily solar irradiation are taken into account, the computed daily average thermal efficiency is also found to be lower for M2U than for M1 and $\mathrm{M} 2 \mathrm{G}$, in agreement with the relative performance predicted by the thermal efficiency curves in Figs 5 and 6 .

\subsection{Dynamic thermal model evaluation}

In order to evaluate the various dynamic collector models, experimental performance data is selected from a day on which the ambient conditions (in particular, solar irradiance) encounter a high degree of timevariation. Figure 15 shows performance data for collector M1 on a day in late November. The period selected for the analysis is between the hours 11:30 to 14:00, during which the solar incidence angle is $\leq 20^{\circ}$. The measured solar irradiance during this period (green line in Fig. 15) shows a number of short-duration peaks due to intermittent cloud cover. The response of the measured solar collector outlet temperature (red line) in response to these peaks in irradiance is attenuated with a slight delay due to the thermal mass of the solar collector.

In Fig. 16, the environmental and operating conditions from the above case are used to simulate the solar collector with three dynamic collector models: (i) a 0-D lumped dynamic model using the calculated value (weighted-component method) of the effective thermal capacity $C_{\mathrm{wt}}$; (ii) a 0-D lumped dynamic model using 


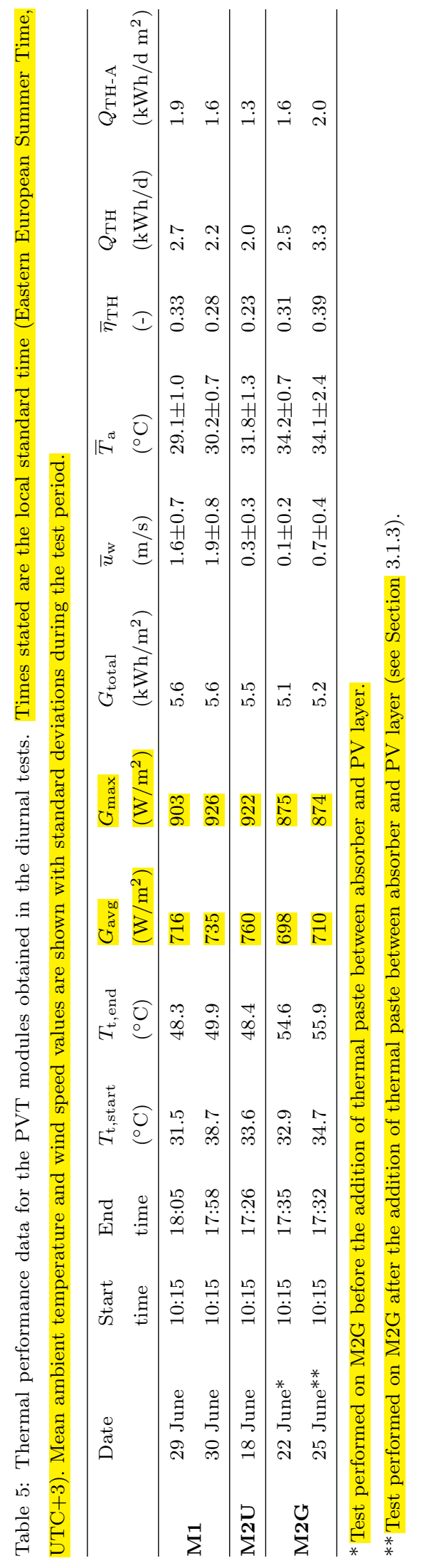




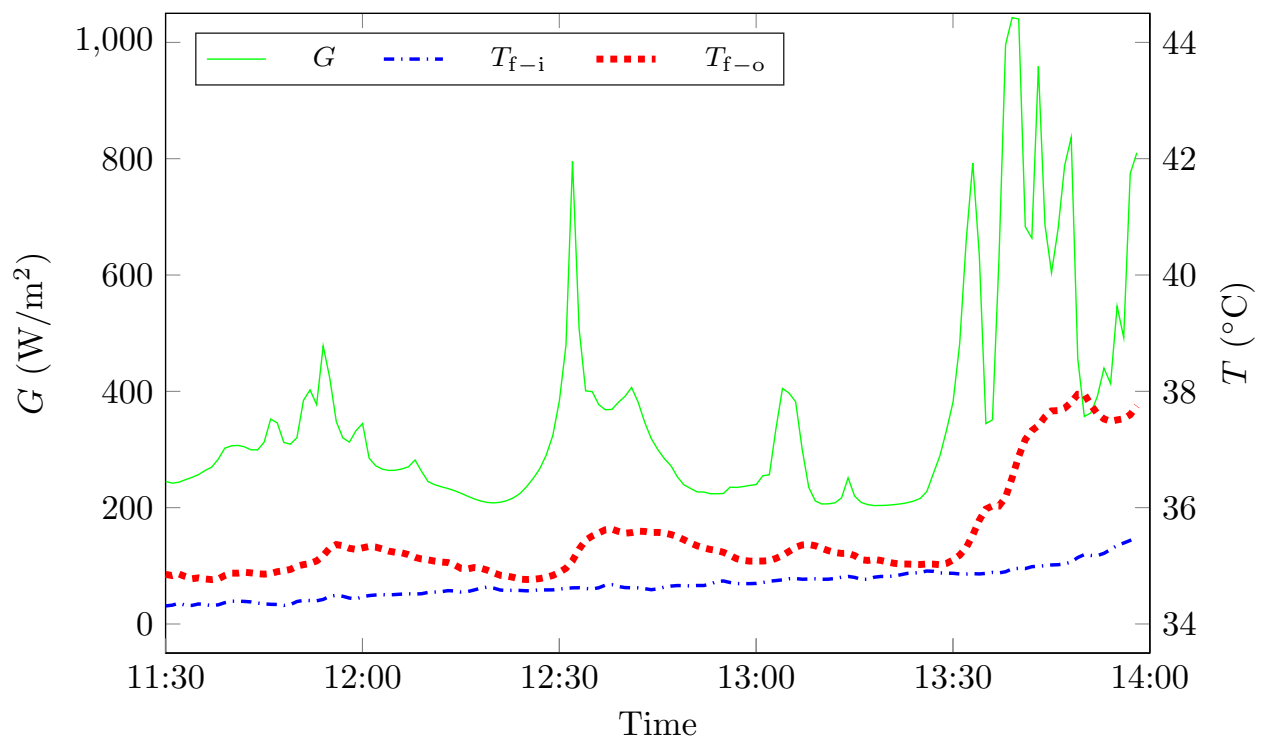

Figure 15: Diurnal test data (collector inlet temperature, collector outlet temperature and solar irradiance) obtained for PVT collector M1 on a cloudy day in November. The data is used to validate the three dynamic solar collector models shown in Fig. 16

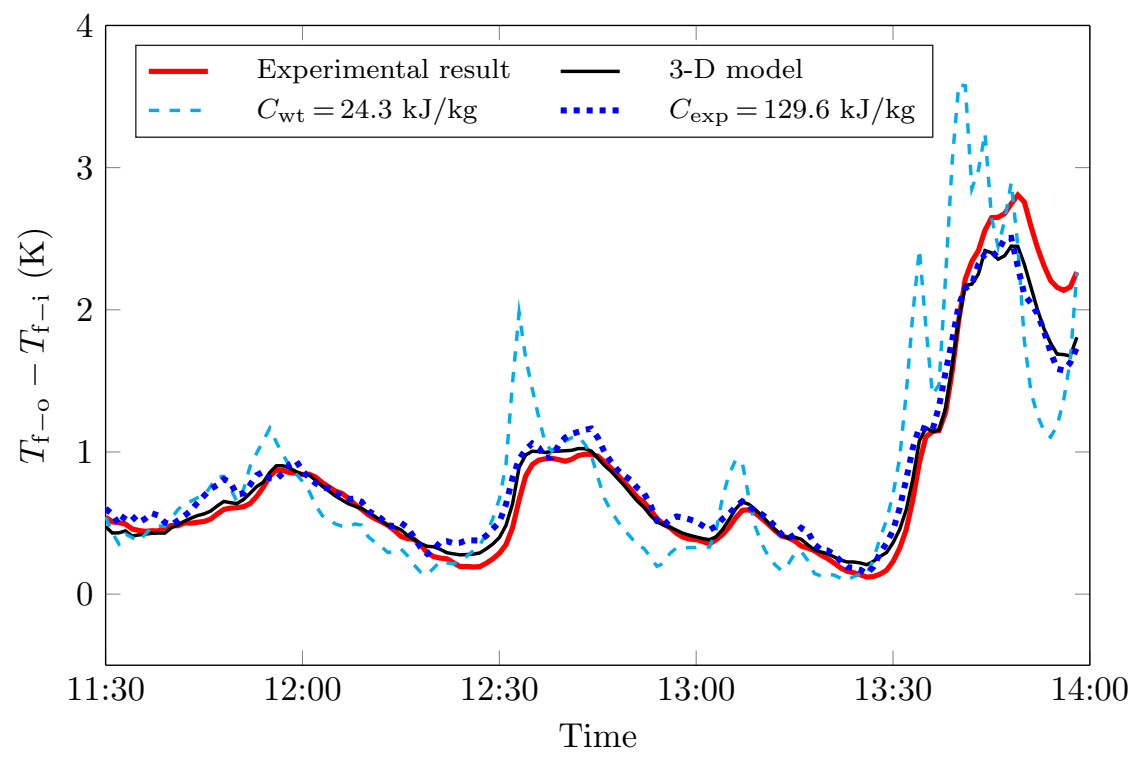

Figure 16: Collector temperature rise simulated by three dynamic models, and compared to the experimental result (solid red line): (i) the 3-D dynamic model (solid black line); (ii) a 0-D (lumped) dynamic model using the experimentally-obtained collector thermal capacity $C_{\exp }$ (dark blue dotted line); and (iii) a lumped dynamic model using the calculated estimate $C_{\mathrm{wt}}$ (light blue dashed line). 


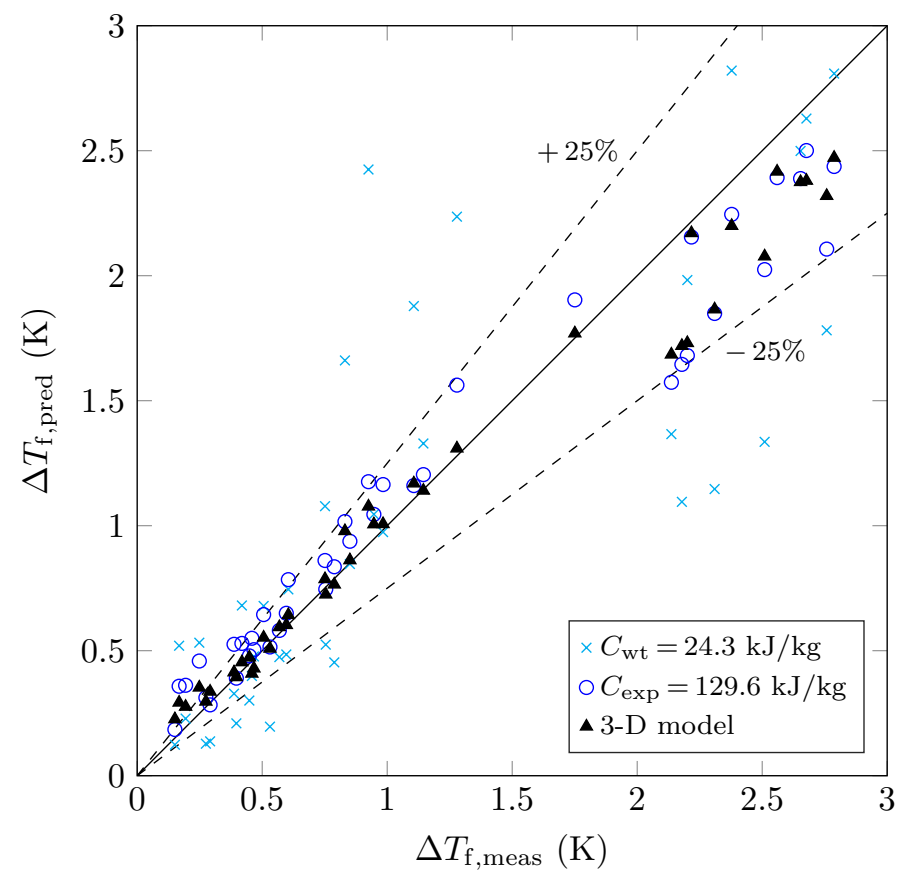

Figure 17: Deviations between measured and predicted values of the fluid temperature rise through the PVT collector, corresponding to the dynamic model simulations in Fig. 16 The solid line passes through $\Delta T_{\mathrm{f}, \text { pred }}=\Delta T_{\mathrm{f}, \text { meas }}$, while the area enclosed by the dashed lines indicates a maximum deviation between measured and predicted values of $\pm 25 \%$.

the experimentally-obtained value of the effective thermal capacity $C_{\text {exp }}$; and (iii) the 3-D dynamic PVT collector model introduced in Section 2.5. The simulation results are compared for the three models to the experimental data in terms of their predictions of the temperature rise through the collector $\left(T_{\mathrm{f}-\mathrm{o}}-T_{\mathrm{f}-\mathrm{i}}\right)$. The deviations between the model predictions and the measured values are reported in Table 6 and Fig. 17.

For the 0-D lumped collector model with the effective thermal capacity input parameter set to $C=$ $C_{\mathrm{wt}}=24.3 \mathrm{~kJ} / \mathrm{K}$, the maximum instantaneous error in the predicted temperature rise through the collector is $1.7 \mathrm{~K}$, while on average there is a $44 \%$ deviation between the model prediction and the measured output. Figure 16 shows that the model underestimates the extent to which the collector's thermal capacity buffers the response of the fluid temperature to the instantaneous peaks in irradiance.

Table 6: Maximum and average deviations between the measured and predicted fluid temperature rise during the PVT collector dynamic performance simulations; performed using the 0-D and 3-D dynamic collector models (see also Figs. 16 and 17 .

\begin{tabular}{llll}
\hline$\left|\Delta T_{\mathrm{f}, \text { pred }}-\Delta T_{\mathrm{f}, \text { meas }}\right|$ & 0 -D model & 0-D model & 3 -D model \\
\hline Maximum deviation & $\left(C=C_{\mathrm{wt}}\right)$ & $\left(C=C_{\text {exp }}\right)$ & $0.5 \mathrm{~K}$ \\
Average deviation & $1.7 \mathrm{~K}$ & $0.7 \mathrm{~K}$ & $0.1 \mathrm{~K}$ \\
Average deviation $(\%)$ & $0.3 \mathrm{~K}$ & $0.1 \mathrm{~K}$ & $14 \%$ \\
\hline
\end{tabular}


For the lumped model with the effective thermal capacity set to $C=C_{\exp }=129.6 \mathrm{~kJ} / \mathrm{K}$ (the average of the experimentally obtained values from the dynamic step-response tests reported in Table 3), the increased buffering of the outlet temperature variations is clearly visible in Fig. 16 . The predicted temperature rise shows far better agreement with the experimental result than the lumped model with the lower thermal capacity value, with an average deviation from the experimental result of $23 \%$ and a maximum prediction error of $0.7 \mathrm{~K}$.

Finally, the collector is simulated using the 3-D dynamic model introduced in Section 2.5. The 3-D model uses the same environmental parameters (solar irradiance, ambient temperature) and operational parameters (inlet temperature, flow-rate) for the simulation as the aforementioned lumped models; but differs from these models in its use of detailed geometric and material data, obtained through detailed inspection and measurements of the PVT collector. The 3-D dynamic model results, plotted in Fig. 16, show the closest agreement of the three models with the experimental result, with an average deviation in the predicted fluid temperature rise of just $14 \%$ and a maximum error of $0.5 \mathrm{~K}$.

It should be noted that the percentage deviations between the model predictions and the measured values of the useful heat output are inherently larger when the temperature rise through the collector is small. This is illustrated in Fig. 17, which shows that for values of $\Delta T_{\mathrm{f}, \text { meas }}>0.5 \mathrm{~K}$ the 3-D model predicts the fluid temperature rise to within $\pm 25 \%$ of the measured value in all instances. It can also be observed that both the 3-D model and 0-D model (with $C=C_{\text {exp }}$ ) are shown to under-predict the fluid temperature rise at the largest values of $\Delta T_{\mathrm{f}}$, indicating that both models overestimate the thermal losses from the collector under intermittent irradiance conditions, despite showing good agreement with measured data across the full range of reduced-temperature values during the steady-state tests.

\subsection{Electrical performance}

When evaluating the electrical efficiency of a PVT collector, the entire top surface area of the PV layer should be exposed to sunlight with no shading. Partial shading of individual cells in a PV panel can cause a disproportionate drop in electrical power output, blocking the flow of electrical current and thereby limiting the output of the remaining unshaded cells. The resulting effect of partial shading on the $I-V$ curve is demonstrated in Fig. 18 for module M1. For the partially shaded module in Fig. $18 \mathrm{~b}$ the $I-V$ curve has multiple peaks, while the maximum power point occurs at a lower voltage compared to the unshaded module in Fig. 18a. This observation is also supported by Refs. 44, 45].

For collectors M1 and M2G, the instantaneous electrical efficiency and open circuit voltage were found to vary approximately linearly with collector temperature during the diurnal monitoring period. The average values of the voltage-temperature gradient $\mathrm{d} V_{\text {oc }} / \mathrm{d} \bar{T}_{\mathrm{c}}$ is reported for collectors M1 and M2G in Table 7 , while the instantaneous electrical and thermal outputs of collectors M1 and M2G are plotted in Fig. 19. M1 has a $50 \%$ larger PV area, and an $8 \%$ higher nominal efficiency than M2G (see Table 1), and the result is an $80 \%$ 
(a)

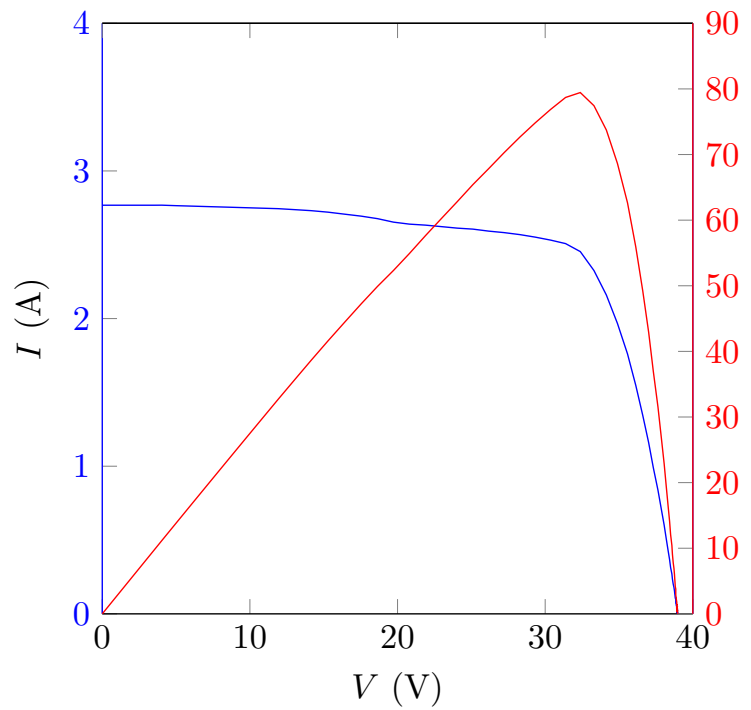

(b)

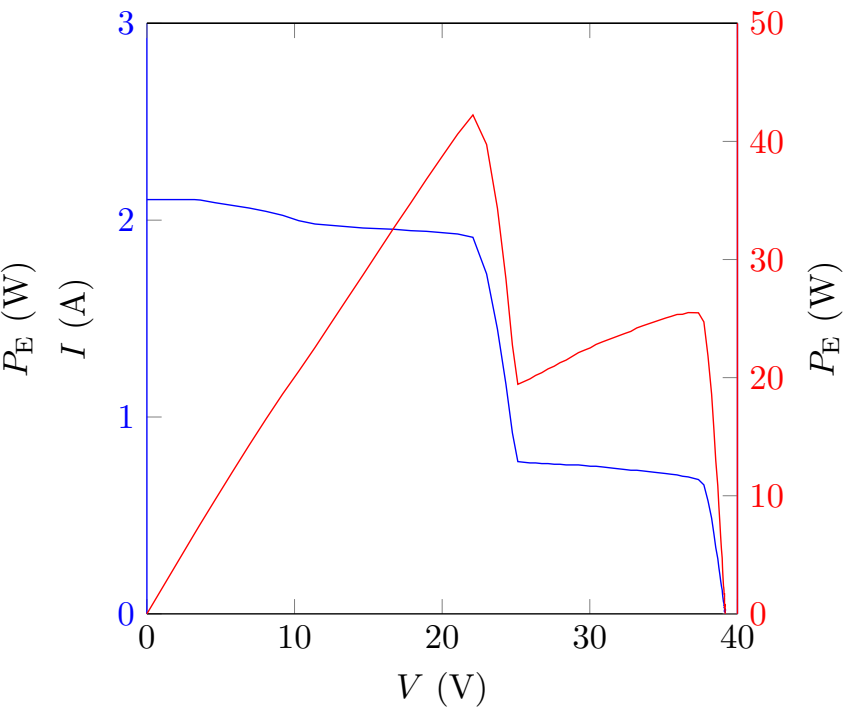

Figure 18: (a) $I-V$ curve (blue) and $P-V$ curve (red) of collector M1 when unshaded, and (b) when partially shaded, during the same day.

(a)

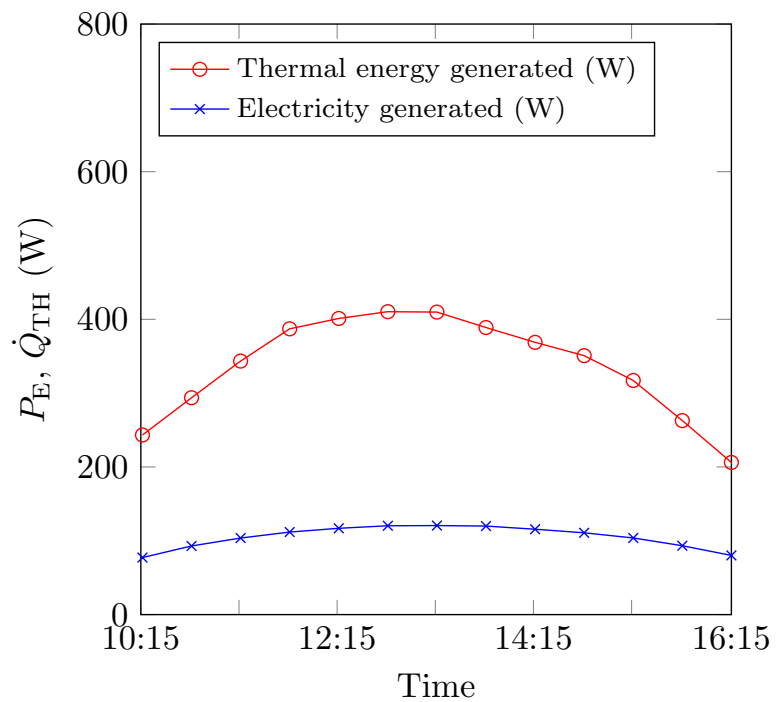

(b)

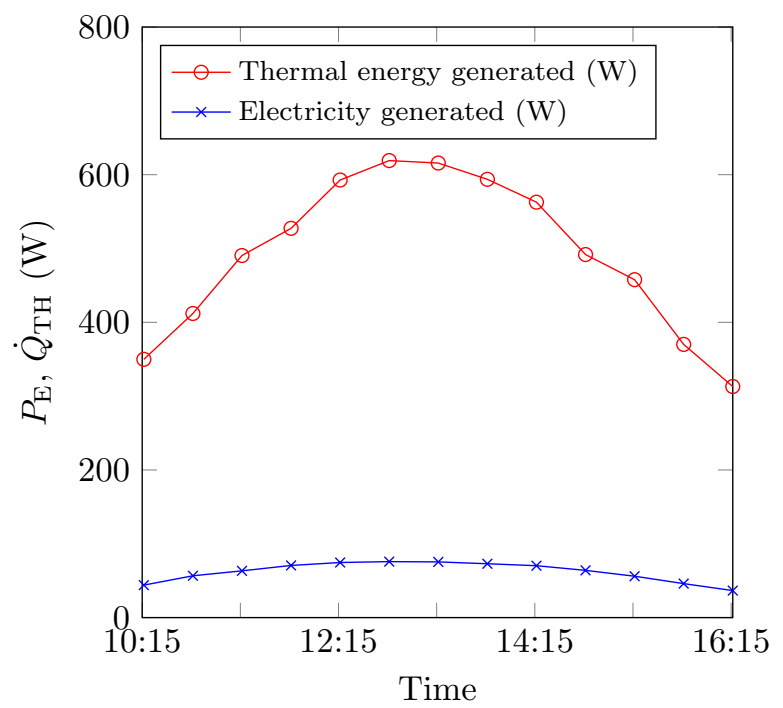

Figure 19: (a) Thermal and electrical energy generated by M1 on the $30^{\text {th }}$ of June; (b) thermal and electrical energy generated by $\mathrm{M} 2 \mathrm{G}$ on the $25^{\text {th }}$ of June. 
higher total electrical energy output over the diurnal monitoring period. Conversely, collector M2G delivers a $>50 \%$ higher total thermal energy output than M1 over the same monitoring period. It should be noted that, compared to the M1 case, the initial tank temperature for the $\mathrm{M} 2 \mathrm{G}$ case was $4{ }^{\circ} \mathrm{C}$ lower and the mean ambient temperature was $4{ }^{\circ} \mathrm{C}$ higher; this is estimated to account for $30-40 \%$ of the observed difference in thermal performance. It should also be noted that $\mathrm{M} 2 \mathrm{G}$ has a lower covering factor, while (as noted in Section 3.1.3 M1 was found to have a particularly poor thermal contact between the absorber fins and the PV layer.

If the total area-related energy output of the solar collectors is considered as the sum of electricity and heat per unit gross area, the two collectors are found to be evenly-matched. M1 generates $2.08 \mathrm{kWh}(\mathrm{E}+\mathrm{TH}) / \mathrm{m}^{2}$ compared to $2.24 \mathrm{kWh}_{(\mathrm{E}+\mathrm{TH})} / \mathrm{m}^{2}$ for M2G. That corresponds to a total energy efficiency of $37 \%$ and $43 \%$, respectively. It is remarkable that, despite the lower electrical energy output due to the smaller PV area, M2G operates with a higher total energy efficiency than the fully covered commercial module M1 with c-Si solar cells.

\section{Conclusions}

In this paper we have presented data from a series of outdoor tests to characterise the electrical and thermal performance of a range of PVT collectors. A novel aspect of this work was the application of steady-state and dynamic test methods adapted from the existing European standard EN 12975-2 for solar-thermal collectors, in the absence of a dedicated testing methodology specifically for PVT collectors. Various design features were investigated, including external glazing, covering factor (ratio of PV area to thermal absorber area), and enhancement of the thermal contact between the PV and absorber layers. The major findings are as follows:

- The addition of a glass cover results in a considerable improvement in thermal performance compared to an unglazed collector, with the first-order heat loss coefficient $a_{1}$ decreasing from 7.07 to $2.17 \mathrm{~W} / \mathrm{m}^{2} \mathrm{~K}$, resulting in $>30 \%$ efficiency at collector temperatures up to $75{ }^{\circ} \mathrm{C}$. However, the reflection losses introduced by the addition of the glazed layer lead to a $10-20 \%$ reduction in electrical output, most notable at large solar incidence angles. This reduction in electrical efficiency is $\sim 3$ times larger than

Table 7: PVT collector electrical performance during diurnal tests.

\begin{tabular}{|c|c|c|c|c|c|c|c|c|}
\hline $\begin{array}{l}\mathrm{PVT} \\
\text { module }\end{array}$ & Date & $\begin{array}{l}\text { Start } \\
\text { time }\end{array}$ & $\begin{array}{l}\text { End } \\
\text { time }\end{array}$ & $\begin{array}{l}E \\
(\mathrm{kWh} / \mathrm{d})\end{array}$ & $\begin{array}{l}E_{\mathrm{A}} \\
\left(\mathrm{kWh} / \mathrm{d} \mathrm{m}^{2}\right)\end{array}$ & $\begin{array}{l}\text { MPP } \\
(\mathrm{W})\end{array}$ & $\begin{array}{l}\bar{\eta}_{\mathrm{E}} \\
(\%)\end{array}$ & $\begin{array}{l}\mathrm{d} V_{\mathrm{OC}} / \mathrm{d} \bar{T}_{\mathrm{c}} \\
(\mathrm{V} / \mathrm{K})\end{array}$ \\
\hline \multirow{2}{*}{ M1 } & 29 June & $10: 15$ & $16: 45$ & 0.69 & 0.48 & 120.8 & 9.4 & 11 \\
\hline & 30 June & $10: 15$ & $16: 45$ & 0.69 & 0.48 & 121.0 & 9.2 & 11 \\
\hline \multirow{2}{*}{ M2G } & 25 June & $10: 15$ & $16: 28$ & 0.38 & 0.24 & 76.2 & 5.1 & 24 \\
\hline & 26 June & $10: 19$ & $16: 11$ & 0.38 & 0.24 & 74.7 & 5.0 & 24 \\
\hline
\end{tabular}


that observed as a result of raising the collector temperature from $30{ }^{\circ} \mathrm{C}$ to $60{ }^{\circ} \mathrm{C}$. Thus the use of high transmittance glass (and in some cases, tracking systems) may be beneficial to achieve higher efficiencies for PVT systems.

- The thermal efficiency under steady-state conditions is $10-15 \%$ lower when the PVT collector is generating electricity at its maximum power point than when operated in open circuit with no electrical load. Small variations in operating voltage lead to large variations in the electrical power output and therefore an accurate maximum power point tracking device (such as an inverter with embedded powertracking capability) should be employed for both electrical and thermal performance testing of PVT collectors.

- The quality of the thermal contact between the PV layer and the rear absorber was found to be an important factor in determining both electrical and thermal performance. Poor thermal contact results in poorer heat transfer to the circulating fluid and higher PV temperatures, resulting in poor electrical performance and, over longer periods, possible thermal degradation of the PV layer. The electrical efficiency temperature coefficient was also found to be far higher when evaluated using the mean collector fluid temperature than would be expected using the PV cell temperature. For the commercial PVT module tested in this study, improvements to the PV-absorber thermal contact resulted in a $6-8 \%$ increase in electrical efficiency and $\mathrm{a} \sim 10{ }^{\circ} \mathrm{C}$ reduction in the temperature measured at the $\mathrm{PV}$ layer. A small increase in thermal efficiency was also observed.

- Dynamic tests revealed a slow thermal response for the commercial PVT collector (time constant of the order of up to $\sim 8 \mathrm{~min})$ when compared to a conventional thermal-only flat plate collector $(<2 \mathrm{~min})$. Furthermore the experimental method results in an effective heat capacity value that is $2-5$ times larger than that obtained from the more widely-used weighted-component calculation method. The dynamic test results were found to be highly sensitive to the operating conditions, making outdoor dynamic testing particularly challenging and time-consuming.

- It is estimated from the findings of this study that the full steady-state and dynamic thermal performance characterisation of a PVT collector under outdoor conditions according to methods specified in EN 12975-2 requires a minimum of 5 days (assuming continuous clear-sky conditions). Previous studies have identified the need to reduce the time and effort required for solar collector testing [17, 46]; thus a validated predictive model for the evaluation of PVT collector designs is suggested here as a cost-effective alternative.

- The 3-D PVT collector model developed in an earlier work by the authors [7] is shown to provide a very good prediction of operation under intermittently cloudy conditions; with a maximum error in the predicted temperature rise through the collector of $0.5 \mathrm{~K}$ during the simulation period, compared to 
maximum errors of $0.7 \mathrm{~K}$ and $1.7 \mathrm{~K}$ for the lumped first-order dynamic models developed in the present work.

\section{Appendix}

Error analysis

The uncertainty associated with the experimental data and calculated parameters has been estimated using the guidelines in EN 12975-2 [8] and the uncertainty analysis methodologies detailed in Holman [47 and Mathiouakis et al. [48].

The uncertainty associated with a directly-measured quantity $x$ over a series of $N$ observations, where some fluctuation of the quantity may take place during the observations, is estimated using the standard deviation of the mean:

$$
u_{x}=\left(\frac{\sum_{i=1}^{N}\left(x_{i}-\bar{x}\right)^{2}}{N(N-1)}\right)^{0.5} .
$$

Measurement errors associated with devices such as sensors, signal amplifiers, data acquisition units etc. are determined through calibration, and where possible fixed errors repeated across measurements are eliminated. For some measurement devices, accuracy values stated in the manufacturers' literature are converted to standard uncertainties using the following equation [48]:

$$
u=\frac{a}{\sqrt{3}} .
$$

If there is more than one independent source of uncertainty associated with a measurement, the final uncertainty of the measured quantity is calculated as follows:

$$
u=\left[\sum_{j} u_{j}^{2}\right]^{0.5} .
$$

Parameters such as the thermal efficiency and the reduced mean temperature are not measured directly but are evaluated from direct measurements of other quantities (such as irradiance, temperature, flow-rates etc.) through a relationship such as $Y=f\left(X_{1}, X_{2}, \ldots X_{\mathrm{n}}\right)$. If the measured quantities $X$ are uncorrelated independent variables then the standard uncertainty of the result $Y$ is calculated as:

$$
u(Y)=\left[\sum_{k=1}^{n}\left(\frac{\partial f}{\partial X_{k}}\right)^{2}\left(u\left(X_{k}\right)\right)^{2}\right]^{0.5} .
$$

\section{Acknowledgement}

This work was supported by the UK Engineering and Physical Sciences Research Council (EPSRC) [grant number EP/M025012/1]. The authors would also like to acknowledge the EU Climate-KIC (http://www.climatekic.org) for IG's PhD studentship, and the AELab-Applied Energy Laboratory (http://www.aelab.gov.cy). Data supporting this publication can be obtained on request from: cep-lab@imperial.ac.uk. 


\section{References}

[1] C. N. Markides, Low-concentration solar-power systems based on organic Rankine cycles for distributedscale applications: Overview and further developments, Frontiers in Energy Research 3 (2015) 47.

[2] M. Herrando, C. N. Markides, K. Hellgardt, A UK-based assessment of hybrid PV and solar-thermal systems for domestic heating and power: System performance, Applied Energy 122 (2014) 288-309.

[3] M. Herrando, A. Ramos, J. Freeman, I. Zabalza, C. N. Markides, Technoeconomic modelling and optimisation of solar combined heat and power systems based on flat-box pvt collectors for domestic applications, Energy Conversion and Management 175 (2018) 67-85.

[4] S. A. Kalogirou, Y. Tripanagnostopoulos, Hybrid PV/T solar systems for domestic hot water and electricity production, Energy Conversion and Management 47 (18) (2006) 3368-3382.

[5] M. Herrando, C. N. Markides, Hybrid PV and solar-thermal systems for domestic heat and power provision in the UK: Techno-economic considerations, Applied Energy 161 (2016) 512-532.

[6] A. Ramos, M. A. Chatzopoulou, I. Guarracino, J. Freeman, C. N. Markides, Hybrid photovoltaicthermal solar systems for combined heating, cooling and power provision in the urban environment, Energy Conversion and Management 150 (2017) 838-850.

[7] I. Guarracino, A. Mellor, N. J. Ekins-Daukes, C. N. Markides, Dynamic coupled thermal-and-electrical modelling of sheet-and-tube hybrid photovoltaic/thermal (PVT) collectors, Applied Thermal Engineering 101 (2016) 778-795.

[8] BS EN 12975-2: 2006, Thermal solar systems and components. Solar collectors. Test methods.

[9] Institute for Solar Energy Database, Institut für Solartechnik (2017).

URL http://www.spf.ch/

[10] J. Cremers, I. Mitina, N. Palla, F. Klotz, X. Jobard, U. Eicker, Experimental analyses of different PVT collector designs for heating and cooling applications in buildings, Energy Procedia 78 (2015) 1889 1894 .

[11] J.-H. Kim, J.-T. Kim, The experimental performance of an unglazed PVT collector with two different absorber types, International Journal of Photoenergy (2012) 6.

[12] J. H. Kim, J. T. Kim, Comparison of electrical and thermal performances of glazed and unglazed PVT collectors, International Journal of Photoenergy 2012.

[13] M. Lämmle, T. Kroyer, S. Fortuin, M. Wiese, M. Hermann, Development and modelling of highlyefficient PVT collectors with low-emissivity coatings, Solar Energy 130 (2016) 161-173. 
[14] M. Ghadiri, M. Sardarabadi, M. Pasandideh-fard, A. J. Moghadam, Experimental investigation of a PVT system performance using nano ferrofluids, Energy Conversion and Management 103 (2015) 468 476.

[15] M. Sardarabadi, M. Passandideh-Fard, S. Z. Heris, Experimental investigation of the effects of silica/water nanofluid on PV/T (photovoltaic thermal units), Energy 66 (2014) 264-272.

[16] IEA-SHC task 43: Solar rating and certification procedure, Tech. rep., International Energy Agency (IEA) (2012).

URL http://archive.iea-shc.org/publications/downloads/Roadmap_SubtaskA.pdf

[17] S. Fischer, W. Heidemann, H. Müller-Steinhagen, B. Perers, P. Bergquist, B. Hellström, Collector test method under quasi-dynamic conditions according to the european standard en 12975-2, Solar Energy 76 (1) (2004) 117-123.

[18] AElab-Applied Energy Laboratory (CY) (2017).

URL http://www.mcit.gov.cy/mcit/aelab/aelab.nsf/index_en/index_en?opendocument

[19] Technical specifications of circulation pump Grandfos UPS 25-60 180 (2017).

URL http://product-selection.grundfos.com/product-detail.product-detail.html? productnumber $=59546800 \& q$ cid $=147827538$

[20] Technical specifications of PVPM2540C (2017).

URL http://pv-engineering.de/en/products/standard-titel/?tt_products\%5Bproduct\%5D=1\& tt_products $\% 5$ Bcat $\% 5 \mathrm{D}=1 \& \mathrm{cHash}=200 \mathrm{~b} 1894 \mathrm{cbdf} 303$ facdd1750b187ded4

[21] Technical specifications of Eplab global pyranometer, model SPP (2017).

URL http://www.eppleylab.com/wp-content/uploads/pdf/EPPLEY160919-SPP.pdf

[22] Technical specifications of Vantage PRO 2 weather station (2017).

URL http://www.davisnet.com/solution/vantage-pro2/

[23] Test report en 12975-2: 2006: Thermal solar systems and components - solar collectors - part2: Test methods, Tech. rep., Eurofins - Modulo Uno S.p.A (2011).

URL http://intergeo.sk/wp-content/uploads/GLAZED-TR-UNIEN12975-2-ENG-ITA-COMPLETO-1. pdf

[24] Technical specifications of Elcora solar thermal collectors (2010).

[25] Technical specifications of Solibro SL2 module, Generation 1.5 (2017).

URL http://solibro-solar.com/fileadmin/image/05_News_Downloads/Downloads/Data_sheets/ G1.5/Solibro_datasheet_SL2_Modul_G1.5_2015-09_Rev04_EN.pdf 
[26] E. Skoplaki, J. Palyvos, On the temperature dependence of photovoltaic module electrical performance: A review of efficiency/power correlations, Solar Energy 83 (5) (2009) 614-624.

[27] T. T. Chow, Performance analysis of photovoltaic-thermal collector by explicit dynamic model, Solar Energy 75 (2) (2003) 143-152.

[28] P. Haurant, C. Ménézo, L. Gaillard, P. Dupeyrat, Dynamic numerical model of a high efficiency PV-T collector integrated into a domestic hot water system, Solar Energy 111 (2015) 68-81.

[29] R. Santbergen, R. J. C. van Zolingen, The absorption factor of crystalline silicon PV cells: a numerical and experimental study, Solar Energy Materials and Solar Cells 92 (4) (2008) 432-444.

[30] M. A. Green, Solar cells: operating principles, technology, and system applications, Englewood Cliffs, NJ, Prentice-Hall, 1985.

[31] H. A. Zondag, D. W. D. De Vries, W. G. J. Van Helden, R. J. C. Van Zolingen, A. A. Van Steenhoven, The thermal and electrical yield of a PV-thermal collector, Solar Energy 72 (2) (2002) 113-128.

[32] R. Viskanta, D. L. Siebers, R. P. Taylor, Radiation characteristics of multiple-plate glass systems, International Journal of Heat and Mass Transfer 21 (6) (1978) 815-818.

[33] J. A. Duffie, W. A. Beckman, Solar engineering of thermal processes, John Wiley \& Sons, 1974.

[34] P. Hoang, V. Bourdin, Q. Liu, G. Caruso, V. Archambault, Coupling optical and thermal models to accurately predict PV panel electricity production, Solar Energy Materials and Solar Cells 125 (2014) $325-338$.

[35] B. Lalović, Z. Kiss, H. Weakliem, A hybrid amorphous silicon photovoltaic and thermal solar collector, Solar cells 19 (2) (1986) 131-138.

[36] B. Lalovic, T. Pavlovic, J. Van Dine, Z. Kiss, L. Shiue, T. Tonon, B. Sieb, X. Wu, Amorphous silicon solar cells on anodically oxidized aluminum substrate, Solar cells 26 (4) (1989) 263-268.

[37] D. De Vries, Design of a photovoltaic/thermal combi-panel, PhD report, Eindhoven University of Technology, 1998.

[38] A. Suzuki, S. Kitamura, Combined photovoltaic and thermal hybrid collector, Japanese Journal of Applied Physics 19 (S2) (1980) 79.

[39] Technical specifications of high temperature and high thermally conductive paste OT-201 (2017). URL http://it.omega.com/temperature/pdf/OT-201.pdf 
[40] D. C. Jordan, S. R. K., Photovoltaic degradation rates - an analytical review, Progress in photovoltaics: Research and Applications 21 (1) (2013) 12-29.

[41] R. Santbergen, Optical absorption factor of solar cells for PVT systems, Technische Universiteit Eindhoven.

[42] M. Green, Silicon solar cells: advanced principles \& practice, Centre for Photovoltaic Devices and Systems, University of New South Wales, 1995.

[43] H. A. Zondag, D. W. De Vries, W. G. J. Van Helden, R. J. C. Van Zolingen, A. A. Van Steenhoven, The yield of different combined PV-thermal collector designs, Solar energy 74 (3) (2003) 253-269.

[44] L. F. L. Villa, D. Picault, B. Raison, S. Bacha, A. Labonne, Maximizing the power output of partially shaded photovoltaic plants through optimization of the interconnections among its modules, IEEE Journal of Photovoltaics 2 (2) (2012) 154-163.

[45] B. I. Rani, G. S. Ilango, C. Nagamani, Enhanced power generation from PV array under partial shading conditions by shade dispersion using Su Do Ku configuration, IEEE Transactions on Sustainable Energy 4 (3) (2013) 594-601.

[46] A. Hofer, D. Büchner, K. Kramer, S. Fahr, A. Heimsath, W. Platzer, S. Scholl, Comparison of two different (quasi) dynamic testing methods for the performance evaluation of a linear fresnel process heat collector, Energy Procedia 69 (2015) 84 - 95.

[47] J. P. Holman, W. J. Gajda, Experimental methods for engineers, Vol. 2, McGraw-Hill New York, 1994.

[48] E. Mathioulakis, K. Voropoulos, V. Belessiotis, Assessment of uncertainty in solar collector modeling and testing, Solar Energy 66 (5) (1999) 337-347. 